\title{
All by myself? Testing descriptive social norm-nudges to increase flood preparedness among homeowners
}

\author{
Jantsje M. Mol ${ }^{1,2 \star}$ (D), W. J. Wouter Botzen ${ }^{1,3,4}$, Julia E. Blasch ${ }^{1}$, Elissa C. Kranzler ${ }^{4}$ \\ and Howard C. Kunreuther ${ }^{4}$ \\ ${ }^{1}$ Institute for Environmental Studies (IVM), Vrije Universiteit Amsterdam, Amsterdam, The Netherlands, \\ ${ }^{2}$ Present address: Center for Research in Experimental Economics and political Decision-making (CREED), \\ University of Amsterdam, Amsterdam, The Netherlands, ${ }^{3}$ Utrecht University School of Economics \\ (U.S.E.), Utrecht University, Utrecht, The Netherlands and ${ }^{4}$ Risk Management and Decision Processes \\ Center, The Wharton School, University of Pennsylvania, Philadelphia, PA, USA \\ ${ }^{*}$ Correspondence to: Jantsje Mol, University of Amsterdam, Roetersstraat 11, 1018 WB Amsterdam, \\ The Netherlands. Email: j.m.mol@uva.nl
}

(Received 30 April 2020; revised 22 February 2021; accepted 24 March 2021)

\begin{abstract}
Nudges based on social norms (norm-nudges) can be compelling behavioral interventions compared with traditional interventions such as taxes and regulations, but they do not work in all circumstances. We tested two empirical norm-nudge frames in an online experiment on taking measures for flood preparedness with large samples of homeowners $(N=1805)$ in two European countries, to evaluate the possible interactions between normnudge effectiveness, individual characteristics, and intercultural differences. We contrasted these norm-nudge treatments with a control and norm-focusing treatment by asking respondents to express their beliefs about what other respondents would do before making a decision relevant to their own payoff. We find no evidence of a treatment effect, suggesting that our social norm-nudges do not affect flood preparedness in the context of a flood risk investment game.
\end{abstract}

Keywords: flood preparedness; homeowners; lab-in-the-field experiment; norm-nudges; social information; social norms

\section{Introduction}

Social norms are rules of behavior that are commonly approved by society, while personal norms represent what people believe to be appropriate behavior for themselves (Bicchieri, 2006). If deviations from a norm are likely to be sanctioned by society, individuals are inclined to follow the norm. A popular behavioral intervention based on social norms is a norm-nudge (Bicchieri \& Dimant, 2019), which stricted re-use, distribution, and reproduction in any medium, provided the original work is properly cited. 
encourages certain behavior by informing individuals about the actions of others, for example by showing energy conservation behavior of neighbors (Allcott, 2011) or tax compliance rates of fellow citizens (Hallsworth et al., 2017). Norm-nudges may prompt people to act the way others are acting, because humans are inclined to model behavior on what others do, or what they believe others do (Bicchieri \& Dimant, 2019).

Norm-nudges are compelling interventions because they are cheap, easy to implement, and less prone to political resistance, compared with traditional interventions such as taxes or regulations (Benartzi et al., 2017). Nevertheless, norm-nudges do not work in all circumstances, and their effectiveness depends on the design of the normnudge (Hummel \& Maedche, 2019). Moreover, there is a risk that a norm-nudge will be ineffective (see, e.g., Chabé-Ferret et al., 2019; Mackay et al., 2019) or even backfire, if not properly tailored to the population and context of interest (Hauser et al., 2018). For example, norm-nudges may backfire when they provide information about normviolating behavior (e.g., tax evasion), which may lower motivations for compliance (Richter et al., 2018). Thus, it is relevant to test different kinds of norm-nudges and empirically assess their effectiveness across contexts.

The aim of this study is to examine the effectiveness of different norm-nudge messages with varying information in increasing individual investments in flood damage mitigation measures. Moreover, this study aims to examine heterogeneity in individual responses to these nudges as well as in the individual investment amounts, including individual characteristics and intercultural differences. We test two empirical norm-nudge frames with a large sample in Spain and the Netherlands and contrast these with a control treatment and a norm-focusing treatment. In the latter, respondents are asked to guess what other respondents would do before making an investment decision relevant to their own payoff. This task has been shown to influence behavior in past work, namely by increasing donations to charity (Bartke et al., 2017) and encouraging prosocial behavior, such as sharing funds.

Many studies on norm-nudges have focused on applications for health, finances, the environment, and energy (Abrahamse \& Steg, 2013; Hummel \& Maedche, 2019). To our knowledge, previous research has not explored the effect of norm-nudges in the context of natural disaster risk-reduction measures such as investment in flood damage mitigation. Over the last few decades, natural hazards such as floods have increasingly impacted society, and this trend is expected to continue in the coming years due to climate change and population and economic growth in disaster-prone areas (IPCC, 2012; Munich, 2018). Floods are among the most costly natural disasters (UNISDR, 2015). Despite the availability of cost-effective measures that limit flood damage to buildings (Aerts et al., 2013), few people in flood-prone areas invest in or implement such measures (Botzen et al., 2019a). This highlights the importance of studying whether norm-nudges can incentivize individuals to invest in costeffective mitigation measures. Examples of cost-effective individual damage-reducing investments include installing dry floodproofing measures that keep water out of the building during a flood (e.g., flood shields) or wet floodproofing measures that minimize damage when water enters a building (e.g., by applying water-resistant building materials). A recent review showed that flood risk management strategies will be much more cost-effective when including individual-level damage-reducing measures 
in addition to structural measures from traditional flood risk management, especially under an increased frequency and severity of floods as a result of climate change (Kreibich et al., 2015).

Investments in individual damage-reducing measures can be considered a public good. For instance, in countries where the government can provide compensation for flood damage, such as the Netherlands, individual investments in reducing flood damage save tax money for compensated victims after flood events. In a previous survey with Dutch homeowners, we elicited social norms with regard to individual flood damage-reducing measures (Mol et al., 2020b). We found that 25\% of Dutch homeowners think that their peers would approve if they invested in damage-reducing measures, $50 \%$ are indifferent, and the remaining $25 \%$ think that their peers would disapprove. Therefore, we believe that investments in flood preparedness are subject to social norms and provide an opportune case for testing social norm-nudges. We focus on descriptive social norm-nudges in this article, because our previous elicitation of injunctive social norms showed that only $10 \%$ of Dutch homeowners indicate that their peers think that they should invest in damage-reducing measures. In our experiment, the norm-nudges refer to the flood protection investment behavior of participants in a previous flood risk game (Mol et al., 2020b) and not to the behavior of peers in real life.

Previous research indicates that flood preparedness behavior is driven by the risk-reduction behaviors of others (Grothmann \& Reusswig, 2006; Poussin et al., 2014). For example, a survey of households in Australia found that perceived social norms had a greater influence on flood insurance purchases than homeowners' perceptions of flood risk (Lo, 2013). In a separate survey, Bubeck et al. (2013) showed a positive relationship between mitigation behavior and having neighbors and friends who implemented flood mitigation measures. However, these studies have not examined the effectiveness of different social norm messages in stimulating individual investments in flood damage mitigation measures.

In this study, we examine the efficacy of several different messages to stimulate flood preparedness measures in a controlled experimental study. As an additional innovation, we compare the impact of social norms on preventive behavior across two countries characterized by different flood risk management regimes. In addition, the populations of these countries differ in the average scores of individualism-collectivism (Pineda et al., 2015), a measure that indicates to what extent people conceptualize themselves in relation to others (Triandis, 1989). Both characteristics may influence the effectiveness of social norm-nudges. We hence assess whether differences in current flood risk management between those countries - with the Netherlands more focused on public flood protection through dikes and Spain on individual protection measures - influence risk attitudes and personal norms for protecting one's home.

Ideally, social norm-nudges are examined in a large-scale field experiment, such as the classical examples on energy conservation and water conservation (Allcott, 2011; Price, 2014). Such a large-scale field experiment was practically infeasible for the case of flood preparedness, because (1) making substantial investments to make a home flood-proof is a more costly behavior than habitual behavior like energy saving or recycling and (2) there is no obvious field partner, such as a utility company, to 
measure and stimulate flood preparedness. An online lab experiment is a feasible and less costly alternative that can give directions for future field experiments, for example by identifying the most promising interventions to be tested in the field. Even though the results of lab experiments often correlate well with self-reported behavior in the field (Dohmen et al., 2011; Dai et al., 2018), the results should be interpreted with caution (Levitt \& List, 2007; Lades et al., 2020).

\section{Literature review}

A growing body of scientific research has identified important aspects of norm-nudge designs (see, e.g., Bicchieri \& Dimant, 2019). One line of research suggests that normnudges are effective only if the targeted behavior is interdependent; that is, when individual preferences are conditional on the empirical expectations of the behavior of others (Bicchieri, 2016). In contrast, when individuals are primarily motivated by their own basic needs or by their beliefs about what is morally right (i.e., targeted behavior is independent), individuals may expect others to behave in one way while behaving in a different way themselves (Bicchieri, 2010). Note that expectations may be normative (what other people would approve of), empirical (what other people do), or both normative and empirical (Bicchieri, 2016). In this article, we use the terminology of Bicchieri et al. (2014). We focus on interdependent behavior under empirical expectations, or descriptive norms - a preference to do $\mathrm{X}$ following the expectation that others do X as well (see Bicchieri \& Dimant, 2019). Note that the term descriptive norm is used slightly differently in the psychological literature, namely as the perception of what is common behavior (Bicchieri \& Dimant, 2019). Alternatively, norm-nudges may be based on injunctive norms, or expectations of what others find appropriate behavior (Cialdini et al., 1990), such as Most people think you should not litter (Farrow et al., 2017).

Another important component of norm-nudge design is choosing the appropriate reference network. According to social identity theory, individuals are much more strongly affected by the actions of others if they share a certain group membership, such as gender, neighborhood, or ethnicity (Tajfel, 1982). For instance, Goldstein et al. (2008) found that referring to a specific reference network in the norm-nudge message other hotel guests who stayed in the same room more effectively promoted towel reuse than a generic message about other hotel guests. Some research suggests that the credibility of the message or message source may alter the effectiveness of norm-nudges. For example, Gifford et al. (2018) claimed that mistrust in messages from government officials could prevent citizens from taking action to combat climate change. However, recent experimental evidence on feedback frames to increase proenvironmental behavior did not demonstrate any evidence of a messenger effect (Hafner et al., 2017). Note that citizens who believe climate change is real may also mistrust government messages if they think the problem is underestimated. Conversely, individuals may feel threatened in their freedom of choice by the nudge, which may prompt them to act in opposition to the desired behavior. For example, Arad and Rubinstein (2018) provided respondents with a nudge to increase savings, which increased the number of respondents selecting the savings arrangement. However, when respondents were told the government used a nudge, some 
respondents opted out of the savings arrangement. A strategy for overcoming this effect is to be transparent about the aim of the nudge, for example by informing respondents that the default option may encourage higher contributions to charity. Recent evidence shows that transparent nudges are judged as more trustworthy (Osman et al., 2018) and might be equally effective as traditional nudges that conceal their aim (Bruns et al., 2018).

Finally, the exact framing of empirical norm-nudge messages may improve their efficacy. For example, Stoffel et al. (2019) studied the effect of different quantifiers (a large number and nearly half) on intentions to participate in cancer screening. They found that both verbal quantifiers increased intentions compared with an exact numerical norm message $(43 \%)$. While most norm-nudge messages are binary (e.g., people pay or do not pay their tax on time, Hallsworth et al., 2017), some contexts allow for a continuous approach (e.g., Neighbors used 1,092 kWh on average, Allcott, 2011). However, many cases of norm-nudges use a binary message, even when the exact distribution of this variable is known.

Contributing to the literature on the transparency of nudges (Bruns et al., 2018), this study tests whether transparently showing the full distribution of choices by previous respondents (i.e., providing the exact percentage of those who chose each option) is more effective than summarizing these choices as a binary message. Furthermore, we measure several individual characteristics that previous research has identified as influencing the effectiveness of social norm messages, such as identification with the reference network (Liu et al., 2019), political identities (Chang et al., 2019), and a concern for social comparison (Buunk \& Gibbons, 2006; Garcia et al., 2013). An additional possible moderator of norm-nudge messages is the extent to which people perceive their relationships with others, which can be measured on a scale ranging from individualist (people conceptualize themselves as individuals) to collectivist (people conceptualize themselves as members of a group) (Triandis, 1989). With regard to social norms, collectivists may be more motivated to follow the behavior of others, implying that people who demonstrate a more collectivist worldview are more inclined to respond to norm-nudge messages (Oh, 2013; Baldwin \& Mussweiler, 2018).

\section{Methodology}

We used an experimental study to examine the impact of different norm-nudge messages on individual flood preparedness in two European countries. Following Hafner et al. (2019), who argued that the effect of norm-nudge messages on behavioral intentions in real life may apply only to respondents who are in the position to execute the intention, we restricted the sample to homeowners. The design included an incentivized investment game in which respondents were asked to make decisions about investing in cost-effective measures to prevent damage of low-probability floods. To mimic the large consequences of real flood investment decisions, we implemented a random lottery incentive mechanism with high monetary stakes (see Camerer \& Hogarth, 1999). Specifically, at the end of the experiment, the software randomly selected one respondent who had the chance to earn up to 650 euro, based on his/her decisions and luck in the game. The payment mechanism 
Floods

You own: your house and you have $64,000 \mathrm{ECU}$ on your savings account

Your home was not flooded.

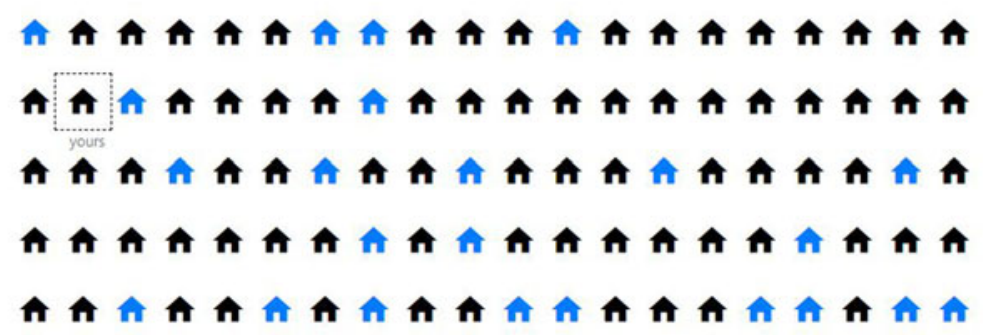

100 homes are depicted above. All homes that have been flooded at least once in the past 25 years, are indicated in blue. Because your home was not flooded, you do not need to pay to recover the damage.

Figure 1. Screenshot of flood risk page.

was explained at the start of the game to motivate subjects to consider their decisions carefully under high stakes.

\section{Investment game}

The investment game was a simplified version of a previous online experiment (Mol et al., 2020b). We used identical parameters to facilitate a comparison of the results. In this game, respondents were asked to imagine owning a house with a flood risk for 25 years. With the hypothetical house comes a savings balance that could be used to make payments in the game, such as purchasing flood damage reduction measures. The currency used in the investment game was ECU (experimental currency units). The game started with the introduction of the parameters: a yearly flood probability of $1 \%$, the maximum damage of 50,000 ECU in case of a flood, and the savings balance of 65,000 ECU. The next page offered five discrete investments with accompanying benefits in terms of reduced damage from flooding. The investment decision was made once, at the start of the game, and damage-reducing measures were effective for the full 25-year period of the game. This one-shot setup of the game was designed to be suitable for the online sample of respondents, accounting for the recommended time span for online surveys.

Figure 1 provides a screenshot of the page in the investment game where the flood risk was realized. This page showed a grid with 100 houses, with the house of the respondent enclosed in a square. The software randomly selected (based on the 1\% flood probability) a number of houses that were flooded in the 25 years of the game and highlighted these in blue. In case the house of the respondent was flooded, the 50,000 ECU damage was subtracted from the savings balance. The optimal 
investment based on expected value calculations was 1000 ECU for a risk neutral $(\theta=1)$ subject with a low time discounting rate $(\delta=0.01)$.

\section{Experimental treatments}

Each respondent was randomly assigned by the software into the control group or one of three treatment groups. In a previous experiment with the flood risk investment game, we compared investments by participants who received a mandatory insurance policy in the game with investments by participants in the control group who did not get any insurance (Mol et al., 2020a). We aimed to power the current experiment such that we would be able to detect an effect size equal to this effect of insurance policy $(d=0.227)$ that was found in the previous experiment. An a priori sample size analysis with a significance level of 0.05 and power of $80 \%$ showed that we would need at least 252 participants per group to detect such an effect. We decided to aim for 250-300 participants in each treatment group. Our budget restricted the number of treatment groups to six. We decided to run all three treatments and the control group in one country $(n=4 \times 300=1200$, the Netherlands $)$ and the most promising treatment plus the control group in the other country $(n=2 \times 300=600$, Spain). This approach was preregistered (https://aspredicted.org/q37kj.pdf). In two treatment groups, we displayed an empirical norm-nudge message with information about decisions of previous respondents. We used the percentages of previous investments in the control treatment ${ }^{1}$ of Mol et al. (2020b) to construct these messages. Note that these percentages were based on decisions of a sample of Dutch homeowners. To prevent confounding effects of in-group/out-group preferences, we did not mention the nationality of the reference group, but simply characterized them as homeowners. A third treatment group faced a focusing norm treatment, by eliciting beliefs about others' investment choices before participating in the investment game (Krupka \& Weber, 2009). We did not include an injunctive norm message because results from our previous experiment showed that $90 \%$ of Dutch homeowners do not think their peers should invest in flood risk reduction. A message highlighting this information has the potential to backfire such that people are less motivated to invest, particularly if they would otherwise expect that a larger proportion of their peers think they should invest, leading to downward adjustment of beliefs (c.f., Bicchieri \& Dimant, 2019). The game was constructed such that individual decisions could not be observed by other respondents to focus on the effect of the norm-nudge messages in isolation from observability effects. In practice, many flood preparedness measures are taken inside a house and cannot be observed by neighbors either, except for the most extreme case of elevating a house. Figure 2a shows the investment screen in the control treatment.

\section{Norm-transparent}

This treatment showed the full distribution of previous flood preparedness decisions in terms of the percentage of investments of previous respondents in five small text

\footnotetext{
${ }^{1}$ This treatment was called 'Mandatory No Insurance' and had exactly the same parameters as the Control treatment in the current experiment.
} 


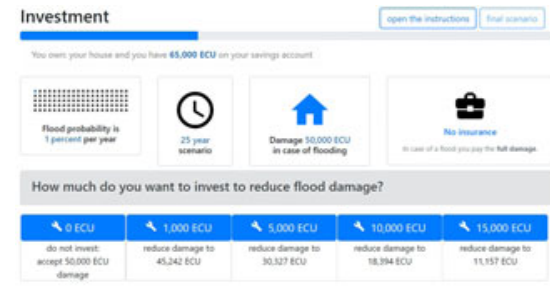

(a) Control

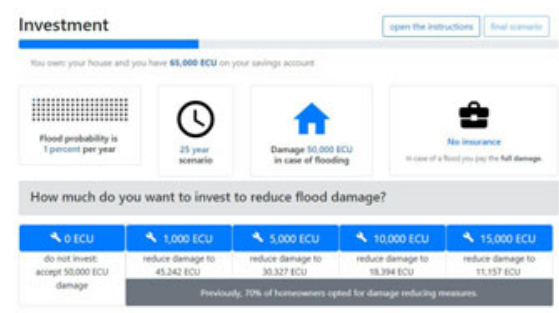

(c) Norm-high

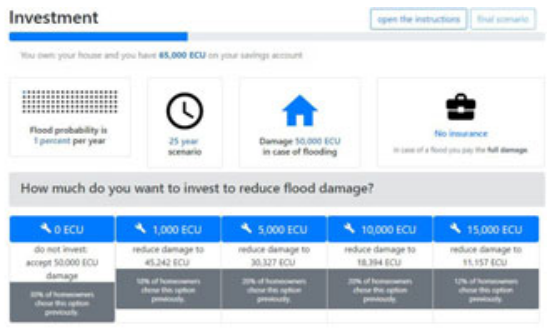

(b) Norm-transparent

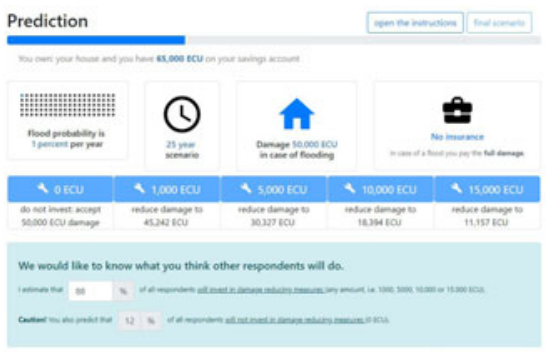

(d) Norm-focusing (belief elicitation)

Figure 2. Screenshots of the four treatments.

boxes below the five investment options (see Figure $2 \mathrm{~b}$ ). We expected that respondents would be unfamiliar with the flood preparedness decision environment. In other words, few respondents are confronted with flood preparedness decisions on a daily basis, ${ }^{2}$ in contrast to other contexts that have been successfully related to social norms, such as energy conservation. Therefore, we expected respondents to have no (strong) beliefs about others' behavior in the investment game. The norm-transparent treatment provided new information on mitigation decisions by others, illustrating the informational effect of a descriptive norm (Krupka \& Weber, 2009). All boxes showed flood preparedness decisions by others in percentages. We presented this information as a percentage in the empirical norm-nudge message following Hallsworth et al. (2017), who found in a large natural field experiment that percentage norm messages are more effective than norm messages presented as a fraction (nine out of ten) or a general statement (the majority) in increasing tax compliance. Note that the online study by Stoffel et al. (2019) found opposite effects: verbal statements (a large number) were most effective in increasing cancer screening intentions. We believed that the findings of Hallsworth et al. (2017) are more relevant for our flood preparedness context, as they also focus on financial behavior, rather than intentions in the health domain.

\footnotetext{
${ }^{2}$ To illustrate, only $9 \%$ of our respondents indicated having purchased private flood insurance coverage and even those respondents probably think about flood insurance only when they pay their premium or renew coverage.
} 


\section{Norm-high}

In the norm-high treatment, an empirical norm-nudge message was displayed directly below the positive investment options (see Figure $2 \mathrm{c}$ ). The message emphasized that a large majority of previous respondents had invested in damage-reducing measures, again by showing a percentage (70\% of respondents in previous research opted for damage-reducing measures). While previous social norms research has mostly focused on binary outcome variables (e.g., whether or not to donate to charity or play a risky lottery), our setup requires respondents to choose from five discrete investment options. The norm-high treatment highlights the binary first step of the decision (invest vs. not invest) and is an intuitive way to describe the distribution.

\section{Norm-focusing}

The final treatment was designed to manipulate the strength of the norm focus (Cialdini et al., 1990; Kallgren et al., 2000). Krupka and Weber (2009) showed in a large lab experiment that the norm focus intervention is effective in increasing prosocial behavior even when respondents believe that others do not behave according to the norm. Recently, Bolton et al. (2020) showed that the mere thought of what other people might do, operationalized with incentivized belief elicitation, leads to the same desired increase of donations compared with a more costly intervention (i.e., with monetary consequences). In line with Krupka and Weber (2009) and Bolton et al. (2020), the dependent variable in our experiment cannot be confounded by strategic concerns. We used an incentive-compatible method to elicit beliefs about others' behavior, before requesting that respondents make a decision about their personal investment in the investment game. We asked respondents to estimate the percentage of other respondents investing in damage-reducing measures $(1000,5000,10,000$, or $15,000 \mathrm{ECU})$. An interactive screen emphasized that the remainder of respondents would not invest (see Figure 2d). We opted for such an explanation to facilitate a comparison of answers with the norm-high treatment, which also showed the percentage of people investing versus not investing. Furthermore, eliciting the full distribution would be a rather complicated task to explain, which could lead to undesirable attrition effects. Belief elicitation was incentivized with an e20 payment on top of the respondent fee for one randomly selected respondent. A large yellow alert marked the transition from the own investment decision to the belief elicitation decision screen. In the control treatment, belief elicitation was conducted after respondents completed the investment game. Figure 3 provides an overview of the experimental treatments.

The experiment started with a short set of sociodemographic questions. Subsequently, the investment game was introduced through several pages of instructions supported with graphics to facilitate the understanding of respondents with different education levels. As in Mol et al. (2020b), the investment game was preceded by a test scenario to familiarize respondents with the decision screens. Before finishing the test scenario stage, respondents were requested to answer a few comprehension questions. The instructions were always accessible to respondents throughout the game. Additionally, the experimental software tracked attempts to answer these comprehension questions and the reopening of instructions. These were included in all regression analyses to control for an understanding of the experimental design. All respondents were paid a fixed participation fee of approximately $€ 1$, and one 


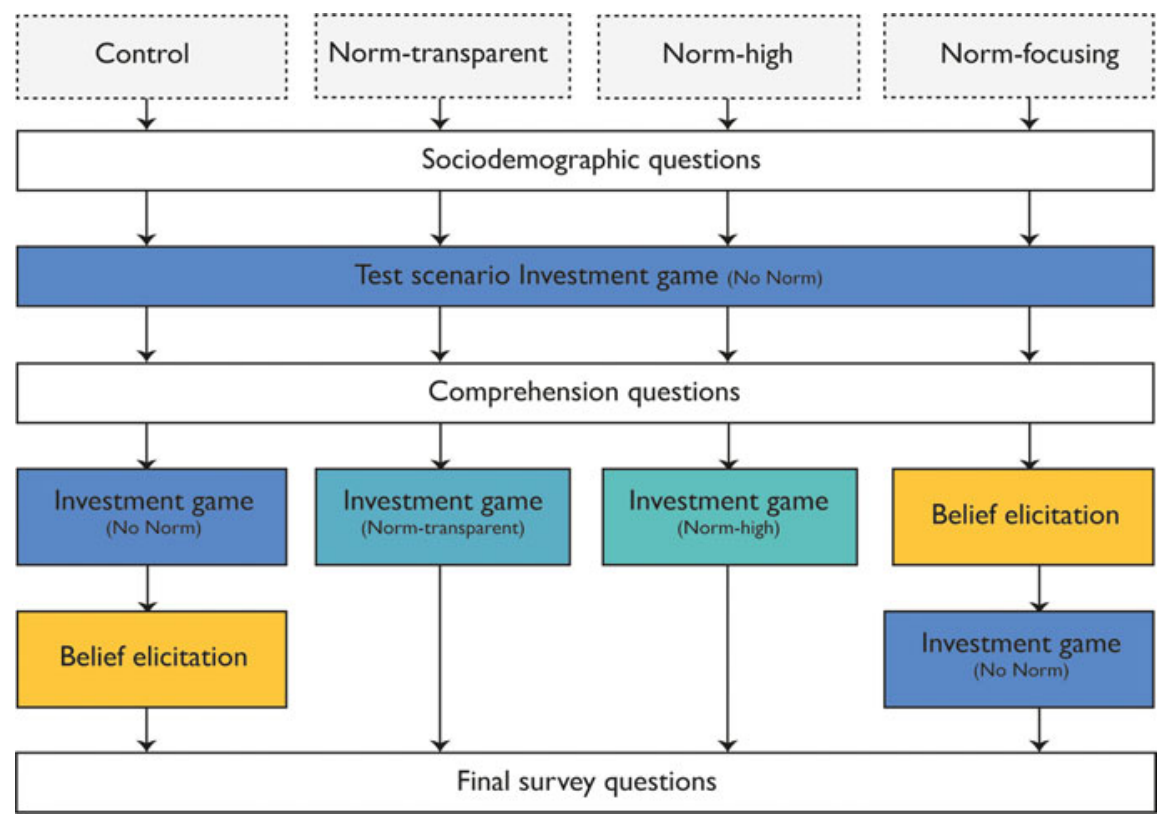

Figure 3. Overview of experiment per treatment.

participant was randomly selected for a large payment corresponding to the bank balance at the end of the experiment at a conversion rate of $100 \mathrm{ECU}=€ 1$, which could range from $€ 100$ to $€ 650$. Participants were informed at the beginning of the experiment that this random selection would take place after all responses had been recorded. The total number of participants was not communicated upfront. All participants agreed to the informed consent page that explained the payment mechanism and the data storage policy. An email address was provided for anyone who would request further information, but no emails were received. We further paid one participant $€ 20$ out of the 57 participants who correctly estimated the share of participants who invested in the game (75\%). The average duration of the experiment was $28 \mathrm{~min}$, and the median duration was $12 \mathrm{~min}$. The duration distribution was rather skewed with some extreme values regarding survey length, because the software did not prevent breaks, which allowed subjects to start the experiment and continue later.

The online experiment was distributed by the survey company Panelinzicht in two rounds: in August 2019 to a sample of Dutch homeowners and in October 2019 to a sample of Spanish homeowners. The panel is representative of the population of each country with respect to education, income, and gender. The experiment was translated into the local language of the respondents (Dutch and Spanish) and administered over the Internet using the experimental software oTree (Chen et al., 2016), which allowed for a similar procedure across countries. The experiment started with a selection question to ensure that only homeowners were eligible to participate. The experimental interface was optimized for the screen size of tablets and desktop computers, which was communicated in the invitation email of the panel company. 
Nevertheless, it was possible to complete the experiment on smaller screens such as smartphones, but this required more effort through zooming and scrolling. The final data set contains 1200 Dutch responses and 605 Spanish responses.

Variables that were part of our hypotheses included trust in the presented information, susceptibility to peer influence, and individualism-collectivism personality scores. These variables were evaluated with survey questions at the end of the investment game. Moreover, we elicited variables that are likely to influence demand for flood damage mitigation investments independent of social norms, such as personal norms, response efficacy of mitigation measures, and risk perception. Table 1 provides an overview of all survey questions administered and the order in which they appeared.

\section{Hypotheses}

We formulated hypotheses based on results from the previous literature. All hypotheses were formally preregistered prior to data collection. ${ }^{3}$ Our main hypothesis concerns the effect of empirical norm-nudge messages on investments in damage-reducing measures in the investment game. Norm-nudges may help individual homeowners to act the way others are acting, as humans are inclined to model behavior on what others do. A large body of literature has shown that norm-nudges may be effective to increase environmental-friendly behavior (Allcott, 2011; Abrahamse \& Steg, 2013). Furthermore, survey research indicates that flood preparedness behavior is driven by the risk-reduction behavior of others (Grothmann \& Reusswig, 2006; Poussin et al., 2014) and perceived social norms ${ }^{4}$ (Lo, 2013). When the information presented as a social norm-nudge differs from respondents' a priori expectation as to what others will do, it may lead them to correct their beliefs. We expect that most respondents perceive few others will invest in flood damage mitigation measures and predict that an empirical norm-nudge message will lead to an increase of investments in flood risk protection measures compared with not including a norm-nudge message.

Hypothesis 1: Respondents confronted with an empirical norm-nudge (norm-high and norm-transparent) will invest more in damage-reducing measures than respondents in the control treatment.

To our knowledge, we are the first to test an empirical norm-nudge showing the percentages of previous decisions for each of the five discrete investment options (normtransparent), as compared with an empirical norm-nudge highlighting the percentage of previous respondents who either have or have not invested (norm-high). Hence, we have no empirical information to hypothesize whether investment in damage-reducing measures will differ between these two norms. We expect that

\footnotetext{
${ }^{3}$ https://aspredicted.org/q37kj.pdf. Preregistered Hypothesis 6 was unrelated to the treatments and is suppressed here for brevity.

${ }^{4}$ Measured as the level in which the respondents believed that their family or friends want them to purchase flood insurance.
} 
Table 1. Summary overview of the survey questions.

\begin{tabular}{|c|c|}
\hline \multicolumn{2}{|l|}{ Demographics } \\
\hline Gender (f32) & Dummy variable gender ( $1=$ respondent is female) \\
\hline Age in years $(f 33)$ & Continuous variable, age in years \\
\hline Master's degree (f35) & Dummy variable education level ( $1=$ holds Master's degree) \\
\hline High income (f36) & $\begin{array}{l}\text { Dummy variable income }(1=\text { monthly household after-tax income }> \\
\qquad 5000)\end{array}$ \\
\hline Expensive house ( $\mathrm{f} 37$ ) & Dummy variable house value $(1=$ house value $>€ 400,000)$ \\
\hline \multicolumn{2}{|l|}{ Hypotheses variables } \\
\hline $\begin{array}{l}\text { Trust in messenger } \\
\text { (f12) }\end{array}$ & $\begin{array}{l}\text { Categorical variable (range 1-5), following Hafner et al. (2017), only } \\
\text { displayed in norm-high and norm-transparent treatments }\end{array}$ \\
\hline Independence (f27) & $\begin{array}{l}\text { Reverse of susceptibility to peer influence. Scale of three categorical } \\
\text { variables (range 1-5), following Eckel et al. (2011) }\end{array}$ \\
\hline Self-responsibility (f25) & $\begin{array}{l}\text { Categorical variable (range 1-5), following Maidl and Buchecker } \\
\text { (2015) }\end{array}$ \\
\hline Collectivism (f30) & $\begin{array}{l}\text { Short 11-item scale (range 1-7) (Cai \& Fink, 2002), revision of INDCOL } \\
\text { scale (Hui \& Triandis, 1986); scores averaged: higher numbers } \\
\text { indicate more collectivism }\end{array}$ \\
\hline $\begin{array}{l}\text { Nationality (from } \\
\text { wave) }\end{array}$ & Dummy nationality $(0=$ the Netherlands, $1=$ Spain $)$ \\
\hline \multicolumn{2}{|l|}{ Control variables } \\
\hline Awareness (s1) & $\begin{array}{l}\text { Dummy sure live in flood-prone area }(1=\text { Yes), adapted from Botzen } \\
\text { et al. (2015) }\end{array}$ \\
\hline Evacuated (s2) & Dummy ever evacuated due to threat of flooding ( $1=$ Yes) \\
\hline Damaged (s3) & Dummy property damaged due to floods in the past $(1=$ Yes $)$ \\
\hline $\begin{array}{l}\text { High damaged amount } \\
(\mathrm{s} 4)\end{array}$ & Dummy variable damaged amount $(1=$ amount $>€ 50,000)$ \\
\hline Flood probability (s5) & $\begin{array}{l}\text { Categorical variables (Zero, Very low, Low, Not low/Not high, High, } \\
\text { Very high, Do not know), adapted from Mol et al. (2020b) }\end{array}$ \\
\hline $\begin{array}{l}\text { Expected water level } \\
\text { (s6) }\end{array}$ & $\begin{array}{l}\text { Expected water level in case of a flood; categorical variables }(0 \mathrm{~cm} \text {, } \\
1-10 \mathrm{~cm}, 11-50 \mathrm{~cm}, 50-100 \mathrm{~cm}, 1-2 \mathrm{~m},>2 \mathrm{~m}) \text {, adapted from Mol } \\
\text { et al. (2020b) }\end{array}$ \\
\hline $\begin{array}{l}\text { High expected damage } \\
\text { (s7) }\end{array}$ & $\begin{array}{l}\text { Dummy high expected damage }(1=\text { respondent expects flood } \\
\text { damage }>\text { e50,000) }\end{array}$ \\
\hline Worry about floods (s8) & Categorical variable (range 1-5), adapted from Botzen et al. (2015) \\
\hline $\begin{array}{l}\text { Threshold of concern } \\
\text { (s9) }\end{array}$ & Categorical variable (range 1-5), adapted from Botzen et al. (2015) \\
\hline Trust in dikes (s10) & Categorical variable (range $1-5)$, adapted from Mol et al. (2020b) \\
\hline Flood probability (s11) & Continuous variable, log of estimate, adapted from Mol et al. (2020b) \\
\hline $\begin{array}{l}\text { Anticipated regret } \\
\text { (f13-15) }\end{array}$ & $\begin{array}{l}\text { Categorical variable (range 1-5), adapted from Kunreuther and } \\
\text { Pauly (2018) }\end{array}$ \\
\hline Difficult (f16) & Categorical variable (range $1-5$ ) on the difficulty of investment game \\
\hline
\end{tabular}


Table 1. (Continued.)

\begin{tabular}{|c|c|}
\hline Strategy (f17) & Open answer to assess strategy in investment game \\
\hline $\begin{array}{l}\text { Measures implemented } \\
\text { (f18) }\end{array}$ & $\begin{array}{l}\text { Continuous variable, number of measures, adapted from Mol et al. } \\
(2020 \mathrm{~b})\end{array}$ \\
\hline $\begin{array}{l}\text { Measures neighbors } \\
\text { (f19) }\end{array}$ & $\begin{array}{l}\text { Dummy respondent knows person who has installed measures ( } 1= \\
\text { Yes), adapted from Mol et al. }(2020 \mathrm{~b})\end{array}$ \\
\hline Measures self ( $\mathrm{f} 20$ ) & $\begin{array}{l}\text { Categorical variable, person responsible for installing measures in } \\
\text { question f3 (Me, Previous owner, Homeowners' association, Other) }\end{array}$ \\
\hline $\begin{array}{l}\text { Neighbors relation } \\
(\mathrm{f} 21)\end{array}$ & $\begin{array}{l}\text { Categorical variable, relationship to person in } \mathrm{f} 19 \text { (Partner, Friend, } \\
\text { Parent, Aunt/Uncle, Son/Daughter, Cousin, Neighbor, Acquaintance, } \\
\text { Other), adapted from Mol et al. (2020b) }\end{array}$ \\
\hline Response efficacy ( $\mathrm{f} 22$ ) & Categorical variable (range 1-5), adapted from Poussin et al. (2014) \\
\hline Response cost (f23) & Categorical variable (range 1-5), adapted from Poussin et al. (2014) \\
\hline Self-efficacy (f24) & Categorical variable (range 1-5), adapted from Poussin et al. (2014) \\
\hline Personal norm (f26) & $\begin{array}{l}\text { Categorical variable (range 1-5), adapted from Doran and Larsen } \\
\text { (2016) }\end{array}$ \\
\hline Risk aversion ( $f 28$ ) & Categorical variable (range $0-10$ ), adapted from Falk et al. (2018) \\
\hline Present bias (f29) & Categorical variable (range $0-10$ ), adapted from Falk et al. (2018) \\
\hline Numeracy (f31) & Short numeracy scale by McNaughton et al. (2015) \\
\hline House type (s34) & Dummy house includes ground floor $(1=$ Yes) \\
\hline House size ( $f 38)$ & $\begin{array}{l}\text { Continuous variable, size of ground floor in } \mathrm{m}^{2} \text {, for calculating } \\
\text { objective risk }\end{array}$ \\
\hline
\end{tabular}

Notes: Order of variable in parentheses: ' $s$ ' indicates start survey and ' $f$ ' indicates final survey. For example, 's7' indicates that it was the seventh question and appeared in the start survey.

respondents in the norm-transparent treatment will have greater trust in the normnudge message than respondents in the norm-high treatment due to the provision of more transparent information in the former condition (see, e.g., Osman et al., 2018).

Hypothesis 2a: Respondents in the norm-transparent treatment have greater trust in the norm-nudge message than respondents in the norm-high treatment.

Accordingly, we expect that respondents in the norm-transparent treatment will be more likely to follow the majority of highlighted responses (investing some amount), relative to those in the norm-high treatment, due to greater levels of trust in the message.

Hypothesis 2b: Respondents in the norm-transparent treatment are more likely to follow the majority of the highlighted responses and invest than respondents in the norm-high treatment.

In the norm-focusing treatment, respondents are confronted with a belief elicitation page before they are asked to make an investment decision for their own payoff. The question, 'What proportion of other respondents would invest in damage-reducing 
measures?' may encourage respondents to think about the norm (Kallgren et al., 2000), which could increase investments even when respondents do not believe many others will invest (Bolton et al., 2020). Based on the large effect sizes in previous research on norm-focusing and norm beliefs (Krupka \& Weber, 2009; Bartke et al., 2017), we expect that the norm-focusing treatment leads to the highest investments of all treatments.

Hypothesis 3: Respondents in the norm-focusing treatment will invest the most in damage-reducing measures, relative to all other treatments.

Susceptibility to peer influence (Dielman et al., 1987; Bearden et al., 1989) may be another important driver of norm-nudge effects. Susceptibility to peer pressure is commonly studied in adolescents and young adults, where it has been found to drive gambling (Langhinrichsen-Rohling et al., 2004) and delinquent (Prinstein et al., 2011) behavior. Eckel et al. (2011) found that high-school students who report being highly independent are less likely to conform to normative behavior in decisions about sharing funds. Recent empirical evidence among adults shows that individuals are more likely to follow provided peer information if they are susceptible to informational influence, across several domains, including investment decisions (Hoffmann \& Broekhuizen, 2009), consumer choice (Orth \& Kahle, 2008), vaccination behavior (FitzSimons et al., 2014), and retirement decisions (Verhallen et al., 2018). In a recent article, Stöckli and Hofer (2020) examined susceptibility to social influence among a large sample of adult online social media users. The authors found that susceptible individuals are more likely to buy what other users post about and to obtain information about political issues following other uses. Thus, we expect to find the same pattern of results.

Hypothesis 4: The effect of the empirical norm-nudge messages is greater for respondents who demonstrate higher levels of susceptibility to peer influence.

The degree to which empirical norm-nudges affect individuals may further be subject to differences in individualism-collectivism. These differences in self-concept can influence engagement in protective behaviors. For example, Parboteeah et al. (2012) found that collectivists are more likely to support sustainability initiatives. Recent evidence shows that people from individualist cultures respond differently to nudges in the context of vaccination behavior (Betsch et al., 2017), in that they are more willing to be vaccinated. Individuals in southern European countries (such as Spain) generally score higher on collectivism than individuals in the Netherlands (Hofstede, 2001; De Raad et al., 2016). Therefore, we expect relevant variation in this variable within our sample that may explain heterogeneity in responses to the social norms message. To investigate the cultural differences of empirical norm-nudges on flood preparedness, we will examine respondents' scores on an 11-item individualism-collectivism scale (Cai \& Fink, 2002), a revised version of the original INDCOL scale (Triandis, 1989). We expect that respondents with a more collectivist worldview are more strongly influenced by an empirical normnudge message, as they are more inclined to follow group behavior. 
Hypothesis 5: The effect of an empirical norm-nudge is larger for individuals with high collectivism scores on the individualism-collectivism scale, relative to those with high individualism scores.

\section{Results}

In this section, we report the experimental results, beginning with descriptive statistics for each preregistered hypothesis. We then turn our attention to a secondary treatment in the Spanish dataset with regard to intention to search for more information about flood risks. Finally, we report a number of observations from an exploratory analysis of the data.

Table 2 presents descriptive statistics of our sample. Demographic variables are very similar across countries, except for income ${ }^{5}$ and home value, ${ }^{6}$ which are in line with the population statistics of each respective country.

\section{Results by hypotheses}

Our main hypothesis concerned the effect of empirical norm-nudge messages on investments in damage-reducing measures in the investment game. Figure 4 shows the proportions of each investment level chosen by our respondents, split per treatment. The shaded areas indicate positive investments $(1000,5000,10,000$, or $15,000 \mathrm{ECU})$, and the remaining white area indicates the proportion of respondents who did not invest anything. We observe almost identical investment levels across treatments and countries. This result is unexpected, given the experimental research on the effectiveness of norm-nudges in the environmental domain (Abrahamse \& Steg, 2013; Farrow et al., 2017; van Valkengoed \& Steg, 2019) and the survey research on the importance of perceived social norms in the flood risk domain (Bubeck et al., 2013; Lo, 2013).

We examined this result more formally with $\chi^{2}$ tests and probit regressions and discuss the results in detail below. Table 3 provides an overview of all hypotheses and reports two-tailed $\chi^{2}$ tests to analyze the differences in frequencies of investments with respect to treatments and independent variables of interest. Hypotheses 4 and 5 predicted interaction effects of susceptibility to peer influence and collectivism on the relationship between norm treatments and damage-reducing investments. Therefore, Table 3 reports $z$-statistics of the interaction term in a probit regression with binary investment as the dependent variable and susceptibility peer influence and collectivism as independent variables.

The first two rows of Table 3 show no support for a main treatment effect as predicted by Hypothesis 1; investments do not differ between respondents in the control group and the norm-high group ( $W=85,493.5, \mathrm{p}=0.11)$, nor between respondents in the control group and the norm-transparent group $(W=87,618.5, \mathrm{p}=0.53)$. Our

\footnotetext{
${ }^{5}$ The average after-tax income is $€ 2368$ per month in Spain (Institute Nacional de Estadística, 2020) and $€ 3042$ per month in the Netherlands (Netherlands Statistics, 2020b).

${ }^{6}$ The average home value is $€ 151,084$ in Spain (Gobierno de España, 2020) and $€ 307,978$ in the Netherlands (Netherlands Statistics, 2020a).
} 
Table 2. Descriptive statistics by country.

\begin{tabular}{|c|c|c|c|}
\hline & Spain & The Netherlands & Total \\
\hline & $(n=605)$ & $(n=1200)$ & $(n=1805)$ \\
\hline \multicolumn{4}{|l|}{ Gender } \\
\hline Male & $302(50 \%)$ & $633(53 \%)$ & 935 (52\%) \\
\hline Female & $303(50 \%)$ & $567(47 \%)$ & $870(48 \%)$ \\
\hline \multicolumn{4}{|l|}{ Age (years) } \\
\hline Mean (SD) & $45( \pm 13)$ & $52( \pm 17)$ & $49( \pm 16)$ \\
\hline \multicolumn{4}{|c|}{ Education level } \\
\hline Low & $99(16 \%)$ & $190(16 \%)$ & $289(16 \%)$ \\
\hline Medium & $201(33 \%)$ & $488(41 \%)$ & $689(38 \%)$ \\
\hline High & $305(50 \%)$ & $522(44 \%)$ & $827(46 \%)$ \\
\hline \multicolumn{4}{|c|}{ Income (per month) } \\
\hline Mean (SD) & $2100( \pm 1200)$ & $3100( \pm 1300)$ & $2800( \pm 1300)$ \\
\hline Missing & $64(10.6 \%)$ & $230(19.2 \%)$ & $294(16.3 \%)$ \\
\hline \multicolumn{4}{|c|}{ Home value $(x € 1000)$} \\
\hline Mean (SD) & $200( \pm 140)$ & $290( \pm 130)$ & $260( \pm 140)$ \\
\hline Missing & $91(15.0 \%)$ & $112(9.3 \%)$ & $203(11.2 \%)$ \\
\hline
\end{tabular}

norm-transparent treatment did not lead to a higher trust in the messenger ( $W=$ 47,932, $\mathrm{p}=0.27$ ) (Hypothesis 2a), and investments were identical in the normtransparent treatment and the norm-high treatment $(W=43,589.5, \mathrm{p}=0.3)$ (Hypothesis 2b). With regard to Hypothesis 3, we find no differences in investments between the norm-focusing group and the control group $(W=181,483, \mathrm{p}=0.8)$, the norm-high group $(W=98,444, \mathrm{p}=0.06)$, and the norm-transparent group ( $W=$ $93,252.5, \mathrm{p}=0.39$ ). The difference in investments between the control group and the norm-transparent treatment is significantly stronger $(z=-2.298, \mathrm{p}=0.02)$ for respondents with high levels of susceptibility to peer influence, which is in line with Hypothesis 4 . However, this result is not found when comparing the control group with the norm-high $(z=-0.662, \mathrm{p}=0.51)$ and norm-focusing $(z=0.707, \mathrm{p}=$ 0.48 ) treatments. Finally, we find no support for Hypothesis 5; the coefficients of the interaction terms between collectivism and the treatment conditions on investments in damage-reducing measures are not significant (norm-focusing: $\mathrm{p}=0.48$; norm-transparent: $\mathrm{p}=0.16$; norm-high: $\mathrm{p}=0.5$ ).

The fact that our statistical tests do not support any differences between experimental treatments should not automatically lead to accepting the null. To examine the possibility of a null result in more detail, we conducted a power analysis. A meaningful effect size to compare our results is the effect of insurance policy compared with a control group without insurance $(d=0.227)$, in a previous experiment that used the flood risk investment game (Mol et al., 2020a). We find that we achieve 


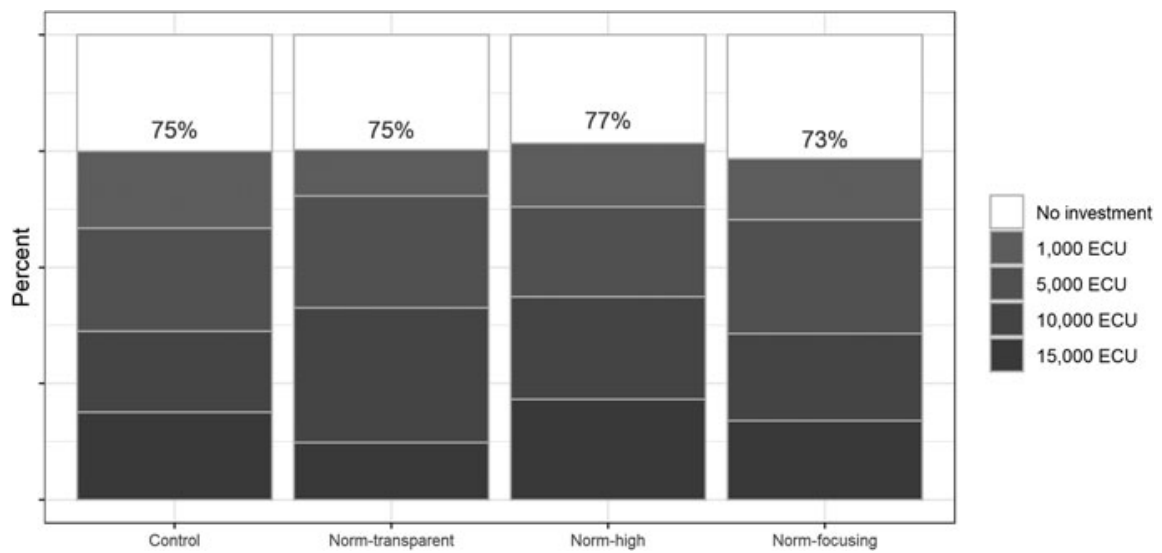

Figure 4. Investments in damage-reducing measures by treatment.

power in excess of $85 \%$ (Hypothesis 2a, norm-transparent vs. norm-high) and up to 93\% (Hypothesis 1, norm-transparent vs. control) to find this effect size. The effect sizes in the current experiment range from 0.01 to 0.12 for pairwise comparisons, and a Kruskal-Wallis test confirms that there are no significant differences in average investments across all treatments $(p=0.26)$. These effect sizes are so small that they are not meaningful: the smallest effect size of interest based on a previous experiment with the same investment game was 0.227 , which is substantially larger than what we find here.

\section{Secondary treatment}

As soon as the data collection for the Dutch respondents was completed, we conducted a preliminary analysis to determine the most promising treatment condition for the Spanish respondents, as indicated in the preregistration. We hypothesized that the nonsignificant effects of norm treatments on investment decisions, as described above, might be attributed to the cost of this investment decision. In other words, changing intentions following the norm treatments is a first step that many are willing to make, while the next step of changing behavior is more difficult to achieve, especially if it requires a costly investment (e.g., time, money, and effort). In our application, the behavioral change of interest is costly by definition: to make or increase a financial investment in flood preparedness measures. In line with previous research (Dur et al., 2021), we speculated that norm-nudge messages are more apt to influence behavioral outcomes for which there is no monetary cost, such as clicking a link to retrieve more information, but less effective at producing changes in behaviors for which there is a tangible cost, such as investing money or increasing savings. To test this alternate explanation, we constructed a button to open a page ${ }^{7}$ with more

\footnotetext{
${ }^{7}$ The following link leads to this document, which is on the website of the Spanish government: https:// www.miteco.gob.es/es/agua/formacion/guia-reduccion-vulnerabilidad-edificios tcm30-379148.pdf.
} 
Table 3. Results by hypotheses.

\begin{tabular}{|c|c|c|c|c|}
\hline Hypothesis & Prediction & Variable & Test & Support \\
\hline $\mathrm{H} 1$ & Norm-high > Control & Investments & $\begin{array}{c}W=85,493.5 \\
p=0.11\end{array}$ & $x$ \\
\hline $\mathrm{H} 1$ & Norm-transparent > Control & Investments & $\begin{array}{c}W=87,618.5 \\
p=0.53\end{array}$ & $x$ \\
\hline $\mathrm{H} 2 \mathrm{a}$ & Norm-transparent > Norm-high & $\begin{array}{l}\text { Trust in } \\
\text { messenger }\end{array}$ & $\begin{array}{c}W=47,932 \\
p=0.27\end{array}$ & $x$ \\
\hline $\mathrm{H} 2 \mathrm{~b}$ & Norm-transparent > Norm-high & Investments & $\begin{array}{c}W=43,589.5 \\
p=0.3\end{array}$ & $x$ \\
\hline $\mathrm{H} 3$ & Norm-focusing $>$ Control & Investments & $\begin{array}{c}W=181,483 \\
p=0.8\end{array}$ & $x$ \\
\hline $\mathrm{H} 3$ & Norm-focusing > Norm-high & Investments & $\begin{array}{c}W=98,444 \\
p=0.06\end{array}$ & $x$ \\
\hline $\mathrm{H} 3$ & Norm-focusing > Norm-transparent & Investments & $\begin{array}{c}W=93,252.5 \\
p=0.39\end{array}$ & $x$ \\
\hline $\mathrm{H} 4$ & $\begin{array}{l}\text { (Susceptible: Norm-focusing > Control) } \\
\text { > (Not susceptible: Norm-focusing > } \\
\text { Control) }\end{array}$ & Investments & $\begin{aligned} z= & -0.654, p \\
& =0.51\end{aligned}$ & $x$ \\
\hline $\mathrm{H} 4$ & $\begin{array}{l}\text { (Susceptible: Norm-transparent > } \\
\text { Control) > (Not susceptible: } \\
\text { Norm-transparent > Control) }\end{array}$ & Investments & $\begin{aligned} z= & -2.298, p \\
& =0.02\end{aligned}$ & $\checkmark$ \\
\hline $\mathrm{H} 4$ & $\begin{array}{l}\text { (Susceptible: Norm-high > Control) > } \\
\text { (Not susceptible: Norm-high }> \\
\text { Control) }\end{array}$ & Investments & $\begin{aligned} z= & -0.662, p \\
& =0.51\end{aligned}$ & $x$ \\
\hline $\mathrm{H} 5$ & $\begin{array}{l}\text { (Collectivist: Norm-focusing > Control) > } \\
\text { (Individualist: Norm-focusing > } \\
\text { Control) }\end{array}$ & Investments & $\begin{aligned} z= & -0.707, p \\
& =0.48\end{aligned}$ & $x$ \\
\hline $\mathrm{H} 5$ & $\begin{array}{l}\text { (Collectivist: Norm-transparent > } \\
\text { Control) > (Individualist: } \\
\text { Norm-transparent }>\text { Control) }\end{array}$ & Investments & $\begin{aligned} z= & -1.39, p \\
& =0.16\end{aligned}$ & $x$ \\
\hline H5 & $\begin{array}{l}\text { (Collectivist: Norm-high > Control) }> \\
\quad \text { (Individualist: Norm-high }>\text { Control) }\end{array}$ & Investments & $\begin{aligned} z= & -0.679, p \\
& =0.5\end{aligned}$ & $x$ \\
\hline
\end{tabular}

Notes: We report $W$ tests for main effects and $z$-scores of probit regressions for hypotheses predicting an interaction. Support indicated for $\mathrm{p}<0.05$.

information about flood risk and mitigation possibilities in Spain. We randomly distributed a descriptive social norm-nudge message based on results from a previous survey (Mol et al., 2020b) to half of the respondents: Recent research shows that $68 \%$ of homeowners have installed at least one measure to protect their home from flood damage (see Figure 5). We expected more clicks on the link for information from respondents who received the norm-nudge message, compared with respondents in the control group. The results demonstrate that only a very small proportion of our sample clicked the link (63 respondents), and we find no differences in information search between these groups $\left(\chi^{2}=0, p=0.989\right)$. 
Final Questionnaire

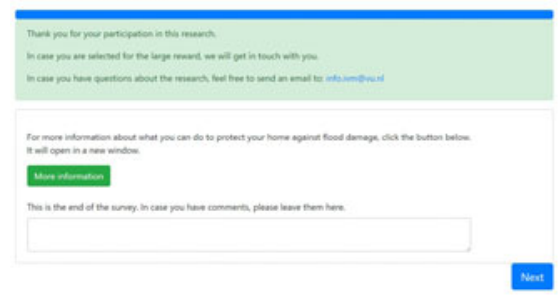

(a) Control
Final Questionnaire

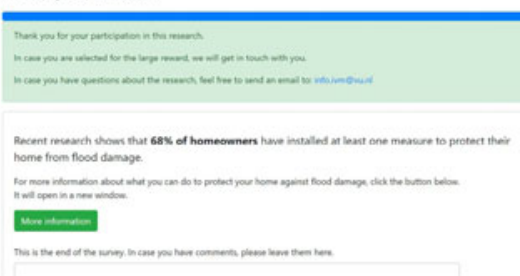

(b) Descriptive social norm-nudge

Figure 5. Screenshots of secondary treatment.

\section{Beliefs}

Next, we investigate the results of our belief elicitation question. On average, $75 \%$ of our respondents (Spanish and Dutch respondents combined) invested at least $1000 \mathrm{ECU}$ (the minimum amount). The correct answer to the belief elicitation question, which asked respondents to indicate the percentage of other respondents investing a positive amount, was thus 75\%. Figure 6 shows the distribution of beliefs about other respondents' investment behavior in our sample, ranging from 0 to 100 . The average belief was $46 \%$ and the median belief was $50 \%$. A majority of respondents underestimated the correct answer, both in the control treatment (72\%) and in the norm-focusing treatment $(70 \%)$. Furthermore, belief responses indicated a preference for round numbers, such as 10,50 , and 80 .

If we assume that beliefs in the norm-transparent and norm-focusing treatments are generally equal to the beliefs elicited in the control treatment, it implies that the information presented in those treatments (namely, that in previous research $70 \%$ of homeowners invested a positive amount) would correct beliefs upward for approximately $72 \%$ of respondents. This illustrates that there was a gap between information and beliefs, which would allow for an upward correction of these beliefs. Yet, an upward adjustment of beliefs did not, in this case, result in an adjustment of behavior. The absence of a treatment effect can, hence, not be explained by the absence of a gap between beliefs and the descriptive norm. However, the opposite effect may be possible: that the information-belief gap is so large that it actually signals that respondents are not aware of any norm with regard to flood preparedness measures, resulting in overall low norm-sensitivity. This would be in line with the argumentation in Bicchieri (2006).

The belief elicitation question was asked in two of our four treatments: control and norm-focusing. The only difference between these treatments was whether the belief elicitation question was asked before (norm-focusing) or after (control) respondents' own investment decisions were taken. We found no difference in belief distributions across treatments (Kolmogorov-Smirnov test, $\mathrm{p}=0.982$ ). The lack of a treatment effect with regard to elicited beliefs suggests that beliefs about others' behavior and investment decisions are made concurrently - it does not matter which question is posed first. Figure 7 shows the relationship between beliefs and one's own investment decisions. The figure demonstrates a positive relationship between investments and 


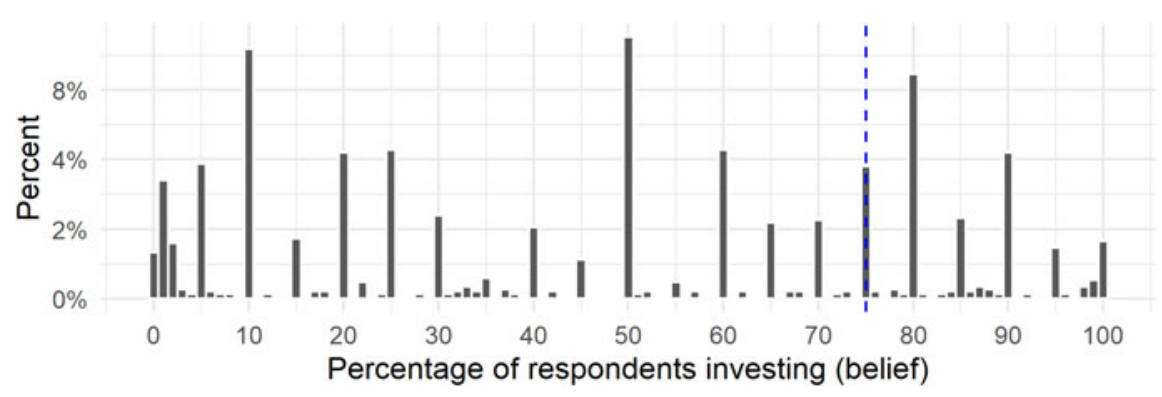

Figure 6. Histogram of beliefs. Note: The blue dotted line indicates the correct answer.

elicited beliefs, implying that investments increase with the belief that more people are investing.

\section{Other correlates of investments}

Prior to our next set of analyses, we explored which variables have the most predictive power when it comes to investments in damage-reducing measures. We estimated simple binary correlations between all hypothesized predictor variables, control variables, and the dependent variable. Figure 8 shows the distribution of the 10 variables with the strongest correlations with decisions in the investment game in order of correlation strength.

\section{Type of respondents}

An alternate explanation for the absence of norm-nudge message effects is that such messages are not effective for respondents who have already decided they want to invest. In contrast, those respondents with no clear preferences with regard to investing, for example those lacking a strong personal norm to invest, or those without positive experiences with measures already installed at home, could be more sensitive to information about other respondents' behavior. As Sunstein (2017) has noted, though nudges may appear to be ineffective at the aggregate level, they may demonstrate effects in distinct subpopulations.

To test this alternate explanation, we constructed two dummy variables to indicate a type of respondent who may be more susceptible to the treatments based on the most important predictors in Figure 8. The strongest predictor of investment in damage reduction is the number of measures already installed at home (see question f18 in Table 1). Therefore, we constructed a dummy of 'No-measures individuals' ( $1=$ zero measure installed at home, $0=$ at least one measure installed at home). Other important predictors from Figure 8 included personal norm, present bias, response efficacy, and expected water level. ${ }^{8}$ We constructed a 'Non-investors' dummy ( $n=$ 369) to indicate individuals who do not expect high water levels (expected water

\footnotetext{
${ }^{8}$ We conducted an additional regression analysis (not reported here) on the decision to mitigate (probit and ordered probit) with the top five predictors. We find that expected water level, response efficacy, and personal norms are robust and significant predictors in either specification.
} 


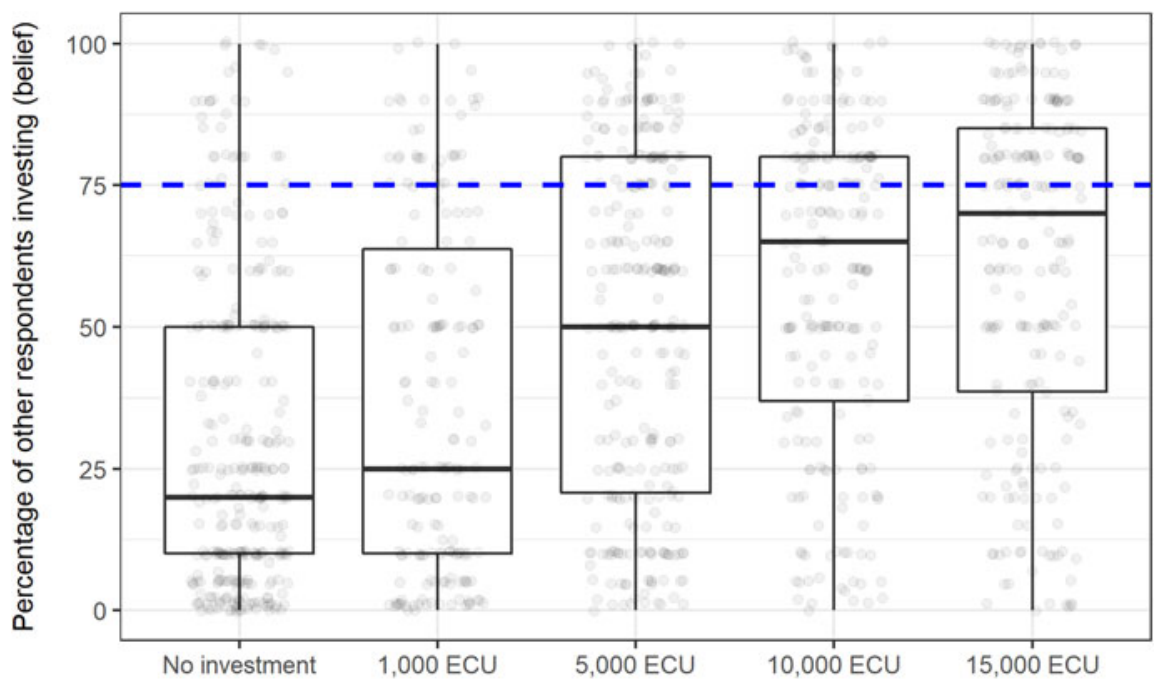

\section{Own investment}

Figure 7. Beliefs of other respondents investing by own investment. Notes: The blue dotted line indicates the percentage of respondents who invested in our sample. Each individual observation is indicated with a gray dot, to which a small arbitrary noise has been added to the $x$ coordinate to facilitate readability. The boxplot whiskers indicate the interquartile range, and the middle lines represent medians.

level in $\mathrm{cm}=0$ ), have low response efficacy (strongly disagree or disagree), and do not have a strong personal norm (strongly disagree or disagree). ${ }^{9}$ After constructing the two dummies to indicate the 'No-measures individuals' and the 'Non-investors' type of respondents, we conducted probit regressions to assess whether the norm-nudge treatments worked differently for these subsamples. The dependent variable in these regressions was binary investment in protection (in the flood risk investment game), and the treatment dummies were included as explanatory variables. The model was estimated separately for each of the different subsamples ('No-measures individuals', 'Measures-individuals', 'Non-investors', and 'Investors'). We expected that the treatment is more effective for the noninvestors or those respondents who have not yet installed any measures at home than for the other samples. We expected that the 'Non-investors' and the 'No-measures individuals' would not be intrinsically motivated, based on the observation that these people do not have a strong personal norm or have not installed any measures at home. Therefore, we expected a larger effect of the treatments for those subsamples, as the treatments are external (they provide information).

Table 4 reports the results of the probit regressions of treatment by type of respondents. Model 1 restricts the sample to 'Investors', whereas Model 2 restricts the sample to the opposite set ('Non-investors'). Model 3 restricts the sample to respondents

\footnotetext{
${ }^{9}$ Although present biased is the third most important predictor, constructing a dummy based on present bias values would require an arbitrary split, which is why we did not use present bias in the construction of the 'Non-investors' dummy.
} 
$\mathrm{Nr}$ of measures installed

Personal norm

Present biased

Expected water level in $\mathrm{cm}$

Probability categorical

\section{Collectivism}

Worry

Not concerned

Risk averse
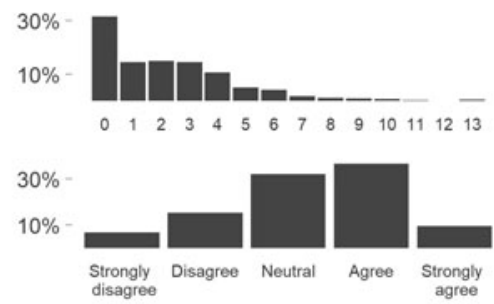

$0.174^{\star \star \star}$

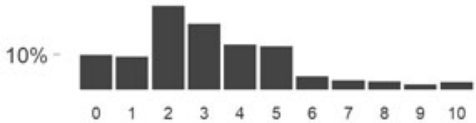

$-0.172^{\star \star \star}$

$0.166^{\star \star \star}$

$0.123^{\star \star \star}$

$0.112^{\star \star \star}$

$0.105^{\star * *}$

$-0.102^{\star \star \star}$

$0.078^{\star \star \star}$

$0.077^{\star \star \star}$

Figure 8. Histograms of flood belief variables and correlations with investment decisions. Note: The stars indicate significant Spearman's correlations $\left({ }^{* \star *} p<0.001\right)$.

who installed at least one measure at home ('Measures'), while Model 4 restricts the sample to respondents who did not install any measure at home ('No measures'). Across all models, we find no effect of treatment on investment in protection for any of the subsamples. As a robustness check, we ran a probit regression analysis (not reported here) on the full sample with interaction terms, all of which were 
nonsignificant. In sum, we find no support for the alternate explanation that normnudge treatments are more effective for a subsample of the respondents, such as those lacking a strong personal norm to invest, or those without positive experiences with measures already installed at home.

\section{Personal norms}

As a next step in our analyses, we explored the differences between personal norms and social norms. As a complement to social norms, personal norms represent what people believe to be appropriate behavior for themselves (Schwartz, 1977), or what they feel morally obliged to do (Harland et al., 1999). Previous research has shown that personal norms can be powerful determinants of proenvironmental behavior (Bamberg \& Möser, 2007; Yazdanpanah \& Forouzani, 2015; Farrow et al., 2017). For example, Doran et al. (2019) showed that personal norms (moral concerns) are a stronger predictor of policy support to mitigate climate change than consequence evaluations. Huber et al. (2020) examined 5 years of longitudinal US household data and found that that personal norms are strongly related to recycling behavior. We measured personal norm as a response on a 5-point scale to the statement, I am morally obligated to take measures to reduce flood risk to my home, adapted from Doran and Larsen (2016). We find that personal norm is significantly correlated with investment decisions (Spearman's correlation $\rho=0.174, \mathrm{p}<0.001$ ), such that stronger personal norms correspond to higher investments. Note that the results on personal norms are correlational, thus providing limited information about causality.

\section{Discussion}

We conducted a high-powered preregistered experiment with homeowners to assess the effectiveness of norm-nudge frames on flood preparedness across countries. We found no evidence of a treatment effect: investments in damage-reducing measures of respondents in the norm-transparent, norm-focusing, and norm-high treatment groups did not differ from investments in the control group. We examined the alternate hypothesis that social norms affect intentions rather than costly behavioral change with a secondary treatment in the Spanish sample, but the results show no difference between the two treatment groups. Furthermore, we analyzed a subset of respondents who were not motivated by individual flood beliefs and personal norms and replicated the null effect of our full sample in this subset. ${ }^{10}$ Several recent examples of studies that do not identify treatment effects of social norm-nudges are in line with our results: in the environmental domain (Chabé-Ferret et al., 2019; Mackay et al., 2019) and the financial domain (Franklin et al., 2019). Generally, it has been noted for various domains, including corruption (Köbis et al., 2019) and obesity

\footnotetext{
${ }^{10} \mathrm{~A}$ possible explanation for the lack of effect of susceptibility to peer influence on our treatments is that we sampled adults from 18 to 90 years old, while most research on susceptibility to peer influence has been conducted on adolescents (Eckel et al., 2011; Prinstein et al., 2011). To control for this explanation, we reran our analysis (not reported here) for Hypothesis 4 on a subset of respondents younger than 25 years old, and we found the same pattern of results as in the full sample.
} 
Table 4. Probit regressions of treatment by type of respondents.

\begin{tabular}{lcccc}
\hline & \multicolumn{3}{c}{ Dependent variable: investment in protection } \\
\cline { 2 - 5 } & $\begin{array}{c}\text { Investors } \\
(1)\end{array}$ & $\begin{array}{c}\text { Noninvestors } \\
\text { (2) }\end{array}$ & $\begin{array}{c}\text { Measures } \\
(3)\end{array}$ & $\begin{array}{c}\text { No measures } \\
(4)\end{array}$ \\
\hline Constant & $0.954^{\star \star \star}$ & 0.061 & $0.847^{\star \star \star}$ & $0.451^{\star \star}$ \\
& $(0.115)$ & $(0.207)$ & $(0.114)$ & $(0.198)$ \\
\hline Treatment (ref = Control) & & & -0.135 & 0.201 \\
\hline Norm-transparent & 0.088 & -0.125 & $(0.149)$ & 0.037 \\
\hline Norm-high & $(0.147)$ & $(0.200)$ & -0.0003 & $(0.192)$ \\
\hline Norm-focusing & 0.182 & -0.157 & $(0.153)$ & -0.103 \\
& $(0.152)$ & $(0.191)$ & -0.023 & $(0.178)$ \\
\hline Country dummy & 0.039 & -0.101 & $(0.123)$ & Yes \\
\hline Log-likelihood & $(0.123)$ & $(0.180)$ & Yes & -240.7 \\
\hline Pseudo $R^{2}$ (McFadden) & Yes & Yes & -445.4 & 0.005 \\
\hline Observations & -442 & -243.9 & 0.002 & 362 \\
\hline
\end{tabular}

Note: Robust standard errors are given in parentheses.

${ }^{\star \star} p<0.05 ;{ }^{\star \star *} p<0.01$.

(Oliver \& Ubel, 2014), that behavioral approaches such as norm-nudges should not be taken as substitutes but rather as supplements to traditional policies.

A recent article by one of the founding fathers of nudging outlined the main reasons for ineffective nudges and three possible responses (Sunstein, 2017). We can rule out one of the two main reasons for failing nudges, namely counternudges, which are nudges aiming to promote the opposite behavior from the original nudge, as they were not at stake in our experiment. The second reason would be that decision makers have strong antecedent preferences, which would be hard to change regardless of the strength of the nudge. We assumed that most respondents were unfamiliar with the flood damage-reducing investment decision, which would argue against strong preferences. Nevertheless, strong preferences with regard to risk aversion, for example, could explain our results.

Comparing our results with prior findings on the effects of social norm-nudges, we find that our results differ from a recent meta-analysis of field experiments using social norms to promote proenvironmental behavior that reveals a mediumsized main effect of social norms compared with control conditions (Bergquist et al., 2019). Nevertheless, the authors find that social norms are less effective when communicated explicitly (i.e., by computerized messages) rather than implicitly (i.e., by cues in the environment) and that the influence of social norms is weaker in nonstudent samples than in student samples. Our design used explicit social norms in a nonstudent sample, which, according to Bergquist et al. (2019), could explain the weak effects. 
We are not the first to report a null effect of social norm-nudges: recent publications have revealed similar findings, and in some empirical studies, there was a backfiring effect of norm-nudge interventions (see, e.g., Fellner et al., 2013; Cranor et al., 2020; Dimant et al., 2020). For example, Fellner et al. (2013) and Cranor et al. (2020) examine the effects of a social norm-nudge on compliance in payments of TV license fees and taxes and find zero effects on compliance. Tyers (2018) uses a social normnudge to try and convince consumers to buy carbon offsets for flight tickets and find no effect. The author argues that the main problem is that carbon offsetting is an unfamiliar concept to most participants, in contrast to other domains where normnudging has been effective, such as recycling, organ donation, or charitable giving. This explanation appears to also reflect our findings. Even though we have no focus group results to back up the claim that respondents are unfamiliar with the flood preparedness decision, several respondents answered the final open-answer feedback question by indicating that they had never thought about the topic before.

An alternate explanation for null effects of social norm-nudges by Dur et al. (2021) states that norm-nudges work well on changing intentions but may ultimately fail to change (costly) behavior. In a field experiment in a retail bank, Dur et al. (2021) find that a social norm-nudge increases intended savings and information search about saving plans, but not actual savings. We find a null effect for both behavior (investments in the flood risk investment game) as well as intentions (information search in the secondary treatment), rejecting this alternate explanation for our results. It should be noted that our study was an online lab experiment, rather than a field experiment that comprises the majority of the literature on social norm interventions. In a study similar to ours, Dimant et al. (2020) examine the effect of social normnudge messages on cheating in an online laboratory experiment and find that their simple norm-nudges are unsuccessful at shifting norms, presumably because a behavioral norm is already in place. Another relevant online lab experiment using normnudge messages is Capraro et al. (2019) that examines simple messages promoting personal norms ('what do you think is the morally right thing to do?'). They show that these messages can effectively increase donation behavior immediately after the nudge, as well as in subsequent choices. These findings are in line with the high correlations between investments in our game and answers to the personal norms statements.

A further potential explanation for the absence of an effect could be that an online lab experiment is an artificial setting that does not perfectly translate into decisions in the field. Nevertheless, findings in Mol et al. (2020b) demonstrate that the flood risk game is generally well suited to illustrate the behavior of homeowners regarding flood risk preparedness. For example, the behavior of the players of the flood risk game under different flood risk probabilities and flood risk insurance schemes (mandatory vs. voluntary, high vs. low deductible) is very much in line with theoretical predictions. This gives us confidence that the general mechanisms leading to higher or lower investments into flood risk preparedness in the game can be transferred - at least qualitatively - to the real world. One additional result that points in this direction is that the Spearman's correlation between investments in the game and the number of flood damage reduction measures implemented by respondents (survey question f18) is positive and significant $(\rho=0.203, \mathrm{p}<0.001)$. Furthermore, our 
finding that flood risk perceptions and the perceived efficacy of flood damage mitigation measures in a real-world context are similar to behavior in the game (see Figure 6) suggests that the lab game may translate into behavior and attitudes in the field. Nevertheless, when interpreting the results, one should keep in mind that the translation of behavior in the lab into relevant domains in the field is never perfect. One way to counter this limitation in future research is to develop a large-scale experiment in cooperation with homeowners' associations and local governments to test the effect of interventions on real-world behavior.

Finally, Czajkowski et al. (2019) compared different variations of descriptive social norm-nudges in a field experiment for household waste sorting with a stated preference approach and found that the willingness to pay for recycling increases with the size of the norm, but that the effect is not monotonic. In other words, high absolute levels of the norm are less effective as they are 'out of reach'. This finding relates to the difference between beliefs (of the current norm) and the information presented in the nudge.

One limitation of our study is that we did not communicate upfront to participants about the probability of being paid, as this was dependent on the total number of participants. A recent theoretical study has shown that to be fully incentivecompatible, the pay-one mechanism should be transparent about the chances of being paid before the start of the experiment (Azrieli et al., 2018). Therefore, we recommend that further research should communicate the chances of being paid clearly and early. Another limitation is that we did not elicit beliefs in the norm-transparent and norm-high treatments. We did not do this, because we did not expect to find independent beliefs about investments in the current sample after providing respondents with the percentages of previous investors. Moreover, we argued that investment data from a previous sample only provide an indication about the nature of investment behavior in the current sample.

In retrospect, it would have been interesting to elicit beliefs in the normtransparent and norm-high treatments to check the consistency of beliefs across treatment groups. Had we found the same distributions of beliefs in the norm-transparent and norm-high treatments as in the control group, we would have inferred that respondents simply ignored our norm-nudge messages. Furthermore, we could have used the beliefs in the norm-transparent and norm-high treatments to test for the 'norm distance effect' (Bergquist \& Nilsson, 2018) that suggests that the power of social norms (messages) is larger when behavior is closer to the (perceived) norm. A second limitation is that the cultural differences between Spain and the Netherlands are not extremely large (Pineda et al., 2015). To obtain a more heterogeneous sample with regard to the individualism-collectivism scale, researchers should consider surveying homeowners in more culturally diverse countries, such as Japan and the USA (Hofstede, 2001).

This study suggests three main takeaways for flood risk communication policies. First, communication to raise risk awareness should take risk-related emotions into account. This recommendation follows from our finding that worry and concern are significant predictors of investments in damage reduction (see Figure 8), which is in line with the previous literature (Kunreuther, 2018). Second, informing homeowners about the effectiveness of damage mitigation measures may enhance flood 
preparedness. This recommendation follows from the strong positive correlation between response efficacy and investments in damage reduction in our study (see Figure 8), confirming previous findings on this topic (Poussin et al., 2014; Mol et al., 2020a). Third, policy makers should pay particular attention to activating personal norms that were found to be associated with flood risk preparedness (as indicated by the strong correlation of personal norms with investments in flood preparedness in Figure 8). These results are in line with Wenzig and Gruchmann (2018), who showed that personal norms generally have a much larger influence on proenvironmental behavior than social norms, and with Botzen et al. (2019b), who showed that personal norms matter more than social norms in a flood risk context. Schwartz (2012) argued that norms need to be activated to be able to influence intention or behavior by being aware of the consequences of actions and feeling responsible. This explanation complements our results in the context of flood risk preparedness, which was framed on the individual level - respondents who feel responsible for their home (i.e., personal norms) invest more in damage-reducing measures than those who do not feel morally obligated to protect their homes. The actions of neighbors and other fellow homeowners (i.e., social norms) may be of lower importance for mitigation decisions in the context of flood preparedness.

We further found a significant negative correlation between present bias and investments in damage-reducing measures. This finding is in line with the previous literature about myopia in the context of preparedness for low-probability/highimpact events, such as floods (Botzen et al., 2019a; Royal \& Walls, 2019). Homeowners perceive the high upfront costs of investing in damage reduction to be much higher than the expected benefits, and when they are presented as biased, they care more about costs now than about benefits later. One way to overcome this bias is through offering low-interest loans that spread the investment costs over time (Meyer \& Kunreuther, 2017; Kunreuther \& Pauly, 2018), which could stimulate flood preparedness. If a nudge in the environmental domain proves ineffective, as we show in the current article, it may warrant the use of stronger measures, such as incentives, regulations, and bans, to influence preparedness (Sunstein \& Reisch, 2013; Carlsson et al., 2019).

\section{Conclusion}

Floods are one of the deadliest and costliest natural disasters worldwide. Fortunately, individual homeowners can invest in several cost-effective measures to prepare their homes for flooding. We attempted to increase investments in flood risk reduction measures in a controlled experiment by subtly nudging respondents (homeowners in the Netherlands and Spain) to consider the social norm of fellow homeowners. In particular, we created different norm-nudge messages by either providing percentages of the population that previously invested in different flood-reduction options (norm-transparent), or the percentage of previous respondents who invested in flood reduction (norm-high). These treatments were contrasted with a control treatment and a norm-focusing treatment, in which respondents' beliefs about normative patterns of flood-reduction investments were elicited. We did not find any evidence of 
a treatment effect, suggesting that our social norm-nudges do not affect the flood preparedness of respondents in a flood risk investment game.

Our results suggest that the problem of underpreparedness for natural disasters cannot be addressed by providing these social norm-nudges, a finding that differs from previous studies that concluded that social norm-nudge messages can be effective ways to facilitate behavioral change in the environmental domain. Our exploratory analyses reveal that there is a strong correlation between beliefs of others' behavior and one's own investments; however, our treatments did not influence either.

A crucial difference between our study and other successful social norm-nudges from the literature is that the flood preparedness context is not a very familiar one for most respondents. Such unfamiliarity may lead to a large information-belief gap; respondents may not be aware of any norm with regard to flood preparedness measures, which could result in overall low norm-sensitivity. Further research could look into this relationship between familiarity and norm-nudge effectiveness. A positive recommendation for further research would be to develop personal or moral norm-nudge messages.

Acknowledgments. We would like to thank conference participants at NoBeC 2019 in Philadelphia, BEEMA5 in Villanova, and WINK Nudging and Beyond in Utrecht for valuable comments. This research has received financial support from the Alfred P. Sloan Foundation (Grant No. G-2018-11100), the Netherlands Organization for Scientific Research (VIDI 452.14.005), and the Wharton Risk Management and Decision Processes Center.

\section{References}

Abrahamse, W. and L. Steg (2013), 'Social influence approaches to encourage resource conservation: A meta-analysis', Global Environmental Change, 23(6): 1773-85.

Aerts, J. C. J. H., W. J. W. Botzen, H. de Moel and M. Bowman (2013), 'Cost estimates for flood resilience and protection strategies in New York City', Annals of the New York Academy of Sciences, 1294(1): 1-104.

Allcott, H. (2011), 'Social norms and energy conservation', Journal of Public Economics, 95(9-10): 1082-95.

Arad, A. and A. Rubinstein (2018), 'The people's perspective on libertarian-paternalistic policies', The Journal of Law and Economics, 61(2): 311-33.

Azrieli, Y., C. P. Chambers and P. J. Healy (2018), 'Incentives in experiments: A theoretical analysis', Journal of Political Economy, 126(4): 1472-503.

Baldwin, M. and T. Mussweiler (2018), 'The culture of social comparison', Proceedings of the National Academy of Sciences of the United States of America, 115(39): E9067-74.

Bamberg, S. and G. Möser (2007), 'Twenty years after Hines, Hungerford, and Tomera: A new meta-analysis of psycho-social determinants of pro-environmental behaviour', Journal of Environmental Psychology, 27(1): 14-25.

Bartke, S., A. Friedl, F. Gelhaar and L. Reh (2017), 'Social comparison nudges - Guessing the norm increases charitable giving', Economics Letters, 152: 73-5. https://doi.org/10.1016/j.econlet.2016.12.023.

Bearden, W. O., R. G. Netemeyer and J. E. Teel (1989), 'Measurement of consumer susceptibility to interpersonal influence', Journal of Consumer Research, 15(4): 473-81.

Benartzi, S., J. Beshears, K. L. Milkman, C. R. Sunstein, R. H. Thaler, M. Shankar, W. Tucker-Ray, W. J. Congdon and S. Galing (2017), 'Should governments invest more in nudging?', Psychological Science, 28(8): 1041-55.

Bergquist, M. and A. Nilsson (2018), 'Using social norms in smart meters: The norm distance effect', Energy Efficiency, 11(8): 2101-9.

Bergquist, M., A. Nilsson and W. P. Schultz (2019), 'A meta-analysis of field-experiments using social norms to promote pro-environmental behaviors', Global Environmental Change, 59(July): 101941.

Betsch, C., R. Böhm, L. Korn and C. Holtmann (2017), 'On the benefits of explaining herd immunity in vaccine advocacy', Nature Human Behaviour, 1(3): 56. 
Bicchieri, C. (2006), The grammar of society: The nature and dynamics of social norms. New York: Cambridge University Press.

Bicchieri, C. (2010), 'Norms, preferences, and conditional behavior', Politics, Philosophy and Economics, 9(3): 297-313.

Bicchieri, C. (2016), Norms in the wild: How to diagnose, measure, and change social norms. New York: Oxford University Press.

Bicchieri, C. and E. Dimant (2019), 'Nudging with care: The risks and benefits of social information', Public Choice, https://doi.org/10.1007/S11127-019-00684-6.

Bicchieri, C., J. W. Lindemans and T. Jiang (2014), 'A structured approach to a diagnostic of collective practices', Frontiers in Psychology, 5: 1418. https://doi.org/10.3389/fpsyg.2014.01418.

Bolton, G., E. Dimant and U. Schmidt (2020), 'Observability and social image: On the robustness and fragility of reciprocity', SSRN Electronic Journal, http://dx.doi.org/10.2139/ssrn.3294375.

Botzen, W. J. W., H. C. Kunreuther and E. O. Michel-Kerjan (2015), 'Divergence between individual perceptions and objective indicators of tail risks: Evidence from floodplain residents in New York City', Judgment and Decision Making, 10(4): 365-85.

Botzen, W. J. W., H. Kunreuther, J. Czajkowski and H. Moel (2019a), 'Adoption of individual flood damage mitigation measures in New York City: An extension of protection motivation theory', Risk Analysis, 39(10): 2143-59.

Botzen, W. J. W., H. C. Kunreuther and E. O. Michel-Kerjan (2019b), 'Protecting against disaster risks: Why insurance and prevention may be complements', Journal of Risk and Uncertainty, 59(2): 151-69.

Bruns, H., E. Kantorowicz-Reznichenko, K. Klement, M. Luistro Jonsson and B. Rahali (2018), 'Can nudges be transparent and yet effective?', Journal of Economic Psychology, 65: 41-59. https://doi.org/10.1016/ j.joep.2018.02.002.

Bubeck, P., W. J. W. Botzen, H. Kreibich and J. C. J. H. Aerts (2013), 'Detailed insights into the influence of flood-coping appraisals on mitigation behaviour', Global Environmental Change, 23(5): 1327-38.

Buunk, A. P. and F. X. Gibbons (2006), 'Social comparison orientation: A new perspective on those who do and those who don't compare with others', in S. Guimond (ed.), Social comparison and social psychologyUnderstanding cognition, intergroup relations, and culture, New York: Cambridge University Press, 15-32.

Cai, D. A. and E. L. Fink (2002), 'Conflict style differences between individualists and collectivists', Communication Monographs, 69(1): 67-87.

Camerer, C. F. and R. M. Hogarth (1999), 'The effects of financial incentives in experiments: A review and capital labor production framework', Journal of Risk and Uncertainty, 19: 7-42. https://doi.org/10.1023/ A:1007850605129.

Capraro, V., G. Jagfeld, R. Klein, M. Mul and I. v. de Pol (2019), 'Increasing altruistic and cooperative behaviour with simple moral nudges', Scientific Reports, 9(1): 11880.

Carlsson, F., C. A. Gravert, V. Kurz and O. Johansson-Stenman (2019), 'Nudging as an environmental policy instrument', SSRN Electronic Journal, 756, http://dx.doi.org/10.2139/ssrn.3711946.

Chabé-Ferret, S., P. Le Coent, A. Reynaud, J. Subervie and D. Lepercq (2019), 'Can we nudge farmers into saving water? Evidence from a randomised experiment', European Review of Agricultural Economics, 46(3): 393-416.

Chang, D., R. Chen and E. L. Krupka (2019), 'Rhetoric matters: A social norms explanation for the anomaly of framing', Games and Economic Behavior, 116: 158-78. https://doi.org/10.1016/j.geb.2019.04.011.

Chen, D. L., M. Schonger and C. Wickens (2016), 'oTree - An open-source platform for laboratory, online, and field experiments', Journal of Behavioral and Experimental Finance, 9: 88-97. http://dx.doi.org/ 10.1016/j.jbef.2015.12.001.

Cialdini, R. B., R. R. Reno and C. A. Kallgren (1990), 'A focus theory of normative conduct: Recycling the concept of norms to reduce littering in public places', Journal of Personality and Social Psychology, 58(6): $1015-26$.

Cranor, T., J. Goldin, T. Homonoff, L. Moore, T. Homono and L. Moore (2020), 'Communicating tax penalties to delinquent taxpayers: Evidence from a field experiment', National Tax Journal, 73(2): 331-60.

Czajkowski, M., K. Zagórska and N. Hanley (2019), 'Social norm nudging and preferences for household recycling', Resource and Energy Economics, 58: 101110.

Dai, Z., F. Galeotti and M. C. Villeval (2018), 'Cheating in the lab predicts fraud in the field: An experiment in public transportation', Management Science, 64(3): 1081-100. 
De Raad, B., F. Morales-Vives, D. P. Barelds, J. P. Van Oudenhoven, W. Renner and M. E. Timmerman (2016), 'Values in a cross-cultural triangle: A comparison of value taxonomies in the Netherlands, Austria, and Spain', Journal of Cross-Cultural Psychology, 47(8): 1053-75.

Dielman, T. E., P. C. Campanelli, J. T. Shope and A. T. Butchart (1987), 'Susceptibility to peer pressure, self-esteem, and health locus of control as correlates of adolescent substance abuse', Health Education \& Behavior, 14(2): 207-21.

Dimant, E., G. A. van Kleef and S. Shalvi (2020), 'Requiem for a nudge: Framing effects in nudging honesty', Journal of Economic Behavior and Organization, 172: 247-66. https://doi.org/10.1016/j.jebo.2020.02.015.

Dohmen, T., A. Falk, D. Huffman, U. Sunde, J. Schupp and G. G. Wagner (2011), 'Individual risk attitudes: Measurement, determinants, and behavioral consequences', Journal of the European Economic Association, 9(3): 522-50.

Doran, R. and S. Larsen (2016), 'The relative importance of social and personal norms in explaining intentions to choose eco-friendly travel options', International Journal of Tourism Research, 18(2): 159-66.

Doran, R., G. Böhm, H. R. Pfister, K. Steentjes and N. Pidgeon (2019), 'Consequence evaluations and moral concerns about climate change: Insights from nationally representative surveys across four European countries', Journal of Risk Research, 22(5): 610-26.

Dur, R. A. J., D. Fleming, M. van Garderen and M. van Lent (2021), A social norm nudge to save more: A field experiment at a retail bank. CESifo Working Paper No. 8894. Retrieved from: https://ssrn.com/ abstract $=3791863$.

Eckel, C., P. J. Grossman, C. A. Johnson, A. C. de Oliveira, C. Rojas and R. Wilson (2011), 'Social norms of sharing in high school: Teen giving in the dictator game', Journal of Economic Behavior and Organization, 80(3): 603-12.

Falk, A., A. Becker, T. Dohmen, B. Enke, D. Huffman and U. Sunde (2018), 'Global evidence on economic preferences', The Quarterly Journal of Economics, 133(4): 1645-92.

Farrow, K., G. Grolleau and L. Ibanez (2017), 'Social norms and pro-environmental behavior: A review of the evidence', Ecological Economics, 140: 1-13. http://dx.doi.org/10.1016/j.ecolecon.2017.04.017.

Fellner, G., R. Sausgruber and C. Traxler (2013), 'Testing enforcement strategies in the field: Threat, moral appeal and social information', Journal of the European Economic Association, 11(3): 634-60.

FitzSimons, D., G. Hendrickx, T. Lernout, S. Badur, A. Vorsters and P. Van Damme (2014), 'Incentives and barriers regarding immunization against influenza and hepatitis of health care workers', Vaccine, 32(38): 4849-54.

Franklin, M., T. Folke and K. Ruggeri (2019), 'Optimising nudges and boosts for financial decisions under uncertainty', Palgrave Communications, 5(1): 1-13.

Garcia, S. M., A. Tor and T. M. Schiff (2013), 'The psychology of competition: A social comparison perspective', Perspectives on Psychological Science, 8(6): 634-50.

Gifford, R., K. Lacroix and A. Chen (2018), 'Understanding responses to climate change', in Susan Clayton, and Christie Manning (eds), Psychology and climate change, chapter 7, Elsevier, 161-83.

Gobierno de España (2020), Real estate appraisals. Technical report, Ministerio de Transportes, Movilidad y Agenda Urbana.

Goldstein, N. J., R. B. Cialdini and V. Griskevicius (2008), 'A room with a viewpoint: Using social norms to motivate environmental conservation in hotels', Journal of Consumer Research, 35(3): 472-82.

Grothmann, T. and F. Reusswig (2006), 'People at risk of flooding: Why some residents take precautionary action while others do not', Natural Hazards, 38(1-2): 101-20.

Hafner, R., D. Elmes and D. Read (2017), 'Exploring the role of messenger effects and feedback frames in promoting uptake of energy-efficient technologies', Current Psychology, 38: 1601-12.

Hafner, R., D. Elmes, D. Read and M. P. White (2019), 'Exploring the role of normative, financial and environmental information in promoting uptake of energy efficient technologies', Journal of Environmental Psychology, 63: 26-35. https://doi.org/10.1016/j.jenvp.2019.03.004.

Hallsworth, M., J. A. List, R. D. Metcalfe and I. Vlaev (2017), 'The behavioralist as tax collector: Using natural field experiments to enhance tax compliance', Journal of Public Economics, 148: 14-31. http:// dx.doi.org/10.1016/j.jpubeco.2017.02.003.

Harland, P., H. Staats and H. A. M. Wilke (1999), 'Explaining proenvironmental intention and behavior by personal norms and the Theory of Planned Behavior', Journal of Applied Social Psychology, 29(12): 2505-28. 
Hauser, O. P., F. Gino and M. I. Norton (2018), 'Budging beliefs, nudging behaviour', Mind \& Society, 17 (1-2): 15-26.

Hoffmann, A. O. I. and T. L. J. Broekhuizen (2009), 'Susceptibility to and impact of interpersonal influence in an investment context', Journal of the Academy of Marketing Science, 37(4): 488-503.

Hofstede, G. (2001), Culture's consequences: Comparing values, behaviors, institutions and organizations across nations. Thousand Oaks, CA: Sage Publications.

Huber, J., W. Kip Viscusi and J. Bell (2020), 'Dynamic relationships between social norms and proenvironmental behavior: Evidence from household recycling', Behavioural Public Policy, 4(1): 1-25.

Hui, C. H. and H. C. Triandis (1986), 'Individualism-collectivism: A study of cross-cultural researchers', Journal of Cross-Cultural Psychology, 17(2): 225-48.

Hummel, D. and A. Maedche (2019), 'How effective is nudging? A quantitative review on the effect sizes and limits of empirical nudging studies', Journal of Behavioral and Experimental Economics, 80 (September 2018): 47-58.

Institute Nacional de Estadística (2020), Living conditions survey. Technical report.

IPCC (2012), Managing the risks of extreme events and disasters to advance climate change adaptation. Cambridge: Cambridge University Press.

Kallgren, C. A., R. R. Reno and R. B. Cialdini (2000), 'A focus theory of normative conduct: When norms do and do not affect behavior', Personality and Social Psychology Bulletin, 26(8): 1002-12.

Köbis, N. C., M. Troost, C. O. Brandt and I. Soraperra (2019), 'Social norms of corruption in the field: Social nudges on posters can help to reduce bribery', Behavioural Public Policy, 1-28. doi:10.1017/ bpp.2019.37.

Kreibich, H., P. Bubeck, M. Van Vliet and H. De Moel (2015), 'A review of damage-reducing measures to manage fluvial flood risks in a changing climate', Mitigation and Adaptation Strategies for Global Change, 20(6): 967-89.

Krupka, E. L. and R. A. Weber (2009), 'The focusing and informational effects of norms on pro-social behavior', Journal of Economic Psychology, 30(3): 307-20.

Kunreuther, H. C. (2018), 'Improving the national flood insurance program', Behavioural Public Policy, 115. doi:10.1017/bpp.2018.26.

Kunreuther, H. C. and M. V. Pauly (2018), 'Dynamic insurance decision-making for rare events: The role of emotions', Geneva Papers on Risk and Insurance: Issues and Practice, 43(2): 335-55.

Lades, L. K., K. Laffan and T. O. Weber (2020), 'Do economic preferences predict pro-environmental behaviour?', Ecological Economics, 183(May): 106977.

Langhinrichsen-Rohling, J., P. Rohde, J. R. Seeley and M. L. Rohling (2004), 'Individual, family, and peer correlates of adolescent gambling', Journal of Gambling Studies, 20(1): 23-46.

Levitt, S. D. and J. A. List (2007), 'What do laboratory experiments measuring social preferences reveal about the real world?', Journal of Economic Perspective, 21(2): 153-74.

Liu, J., J. M. Thomas and S. Higgs (2019), 'The relationship between social identity, descriptive social norms and eating intentions and behaviors', Journal of Experimental Social Psychology, 82: 217-30. https:// doi.org/10.1016/j.jesp.2019.02.002.

Lo, A. Y. (2013), 'The role of social norms in climate adaptation: Mediating risk perception and flood insurance purchase', Global Environmental Change, 23(5): 1249-57.

Mackay, M., S. Yamazaki, S. Jennings, H. Sibly, I. E. van Putten and T. J. Emery (2019), 'The influence of nudges on compliance behaviour in recreational fisheries: A laboratory experiment', ICES Journal of Marine Science, 77(6): 2319-32.

Maidl, E. and M. Buchecker (2015), 'Raising risk preparedness by flood risk communication', Natural Hazards and Earth System Sciences, 15(7): 1577-95.

McNaughton, C. D., K. L. Cavanaugh, S. Kripalani, R. L. Rothman and K. A. Wallston (2015), 'Validation of a short, 3-item version of the subjective numeracy scale', Medical Decision Making, 35(8): 932-36.

Meyer, R. J. and H. C. Kunreuther (2017), The ostrich paradox: Why we underprepare for disasters. Philadelphia, PA: Wharton School Press.

Mol, J. M., W. J. W. Botzen and J. E. Blasch (2020a), 'Risk reduction in compulsory disaster insurance: Experimental evidence on moral hazard and financial incentives', Journal of Behavioral and Experimental Economics, 84(February): 101500. 
Mol, J. M., W. J. W. Botzen and J. E. Blasch (2020b), 'Behavioral motivations for self-insurance under different disaster risk insurance schemes', Journal of Economic Behavior \& Organization, 180: 96791. https://doi.org/10.1016/j.jebo.2018.12.007.

Munich, R. E. (2018), Hurricanes cause record losses in 2017 - The year in figures. Available at: https://www. munichre.com/topics-online/en/climate-change-and-natural-disasters/natural-disasters/2017-year-infigures.html.

Netherlands Statistics (2020a), Existing own homes. Technical report.

Netherlands Statistics (2020b), Inkomen van huishoudens. Technical report.

Oh, S. H. D. (2013), 'Do collectivists conform more than individualists? Cross-cultural differences in compliance and internalization', Social Behavior and Personality, 41(6): 981-94.

Oliver, A. and P. Ubel (2014), 'Nudging the obese: A UK-US consideration', Health Economics, Policy and Law, 9(3): 329-42.

Orth, U. R. and L. R. Kahle (2008), 'Intrapersonal variation in consumer susceptibility to normative influence: Toward a better understanding of brand choice decisions', Journal of Social Psychology, 148(4): 423-48.

Osman, M., N. Fenton, T. Pilditch, D. Lagnado and M. Neil (2018), 'Whom do we trust on social policy interventions?', Basic and Applied Social Psychology, 40(5): 249-68.

Parboteeah, K. P., H. M. Addae and J. B. Cullen (2012), 'Propensity to support sustainability initiatives: A cross-national model', Journal of Business Ethics, 105(3): 403-13.

Pineda, A., V. Hernández-Santaolalla and M. del Mar Rubio-Hernsández (2015), 'Individualism in Western advertising: A comparative study of Spanish and US newspaper advertisements', European Journal of Communication, 30(4): 437-53.

Poussin, J. K., W. J. W. Botzen and J. C. J. H. Aerts (2014), 'Factors of influence on flood damage mitigation behaviour by households', Environmental Science and Policy, 40: 69-77. http://dx.doi.org/10.1016/ j.envsci.2014.01.013.

Price, M. K. (2014), 'Using field experiments to address environmental externalities and resource scarcity: Major lessons learned and new directions for future research', Oxford Review of Economic Policy, 30(4): 621-38.

Prinstein, M. J., W. A. Brechwald and G. L. Cohen (2011), 'Susceptibility to peer influence: Using a performance-based measure to identify adolescent males at heightened risk for deviant peer socialization', Developmental Psychology, 47(4): 1167-72.

Richter, I., J. Thøgersen and C. Klöckner (2018), 'A social norms intervention going wrong: Boomerang effects from descriptive norms information', Sustainability, 10(8): 2848.

Royal, A. and M. Walls (2019), 'Flood risk perceptions and insurance choice: Do decisions in the floodplain reflect overoptimism?', Risk Analysis, 39(5): 1088-104.

Schwartz, S. H. (1977), 'Normative influences on altruism', Advances in Experimental Social Psychology, 10(C): 221-79.

Schwartz, S. H. (2012), 'An overview of the Schwartz theory of basic values', Online Readings in Psychology and Culture, 2(1): 1-20.

Stöckli, S. and D. Hofer (2020), 'Susceptibility to social influence predicts behavior on Facebook', PLoS ONE, 15(3): 1-20.

Stoffel, S. T., M. Goodwin, M. Sieverding, I. Vlaev and C. von Wagner (2019), 'Testing verbal quantifiers for social norms messages in cancer screening: Evidence from an online experiment', BMC Public Health, 19(1): 658 .

Sunstein, C. R. (2017), 'Nudges that fail', Behavioural Public Policy, 1(1): 4-25.

Sunstein, C. R. and L. A. Reisch (2013), 'Green by default', Kyklos, 66(3): 398-402.

Tajfel, H. (1982), 'Social psychology of intergroup relations', Annual Review of Psychology, 33(1): 1-39.

Triandis, H. C. (1989), 'The self and social behavior in differing cultural contexts', Psychological Review, 96(3): 506-20.

Tyers, R. (2018), 'Nudging the jetset to offset: Voluntary carbon offsetting and the limits to nudging', Journal of Sustainable Tourism, 26(10): 1668-86.

UNISDR (2015), The human costs of weather related disasters. Technical report, UNISDR.

van Valkengoed, A. M. and L. Steg (2019), 'Meta-analyses of factors motivating climate change adaptation behaviour', Nature Climate Change, 9(2): 158-63. 
Verhallen, P., E. Brüggen, T. Post and G. Odekerken-Schrrder (2018), 'Norms in behavioral interventions: Peer or anchoring effects?', SSRN Electronic Journal, http://dx.doi.org/10.2139/ssrn.3098028.

Wenzig, J. and T. Gruchmann (2018), 'Consumer preferences for local food: Testing an extended norm taxonomy', Sustainability, 10(5): 1-23.

Yazdanpanah, M. and M. Forouzani (2015), 'Application of the Theory of Planned Behaviour to predict Iranian students' intention to purchase organic food', Journal of Cleaner Production, 107: 342-52. http://dx.doi.org/10.1016/j.jclepro.2015.02.071.

Cite this article: Mol JM, Botzen WJW, Blasch JE, Kranzler EC, Kunreuther HC (2021). All by myself? Testing descriptive social norm-nudges to increase flood preparedness among homeowners. Behavioural Public Policy 1-33. https://doi.org/10.1017/bpp.2021.17 